\title{
Dust accumulated fungi in air-conditioning system: Findings based on field and laboratory experiments
}

\author{
Zhijian Liu' $(\varangle)$, Yuzhu Deng' ${ }^{1}$, Shengyuan Ma', Bao-Jie He² (ه), Guoqing Cao ${ }^{3}$ \\ 1. Department of Power Engineering, North China Electric Power University, Baoding, Hebei 071003, China \\ 2. Faculty of Built Environment, University of New South Wales, NSW Sydney 2052, Australia \\ 3. Institute of Building Environment and Energy, China Academy of Building Research, Beijing 100013, China
}

\begin{abstract}
This study analyzes the growth and reproduction of dust accumulated fungi (DAF) in an airconditioning system based on field measurement and molecular biology, laboratory experiment and prediction modelling. The field measurement was conducted to collect dust in filter screen, surface cooler and air supply duct of two air handling units (AHUs). The results indicate that dust volume and fungal number in two AHUs generally met the hygienic specification of public buildings, but the cleansing did not fulfil requirements. High-throughput sequencing was conducted, revealing that the dominant fungal species were Alternaria_betae-kenyensis, Cladosporium_delicatulum, Aspergillus_sydowii, Verticillium_dahliae. Laboratory experiment was conducted to analyze the impact of several factors (e.g. growth time, temperature, relative humidity, duct material) and their combination on the DAF growth. The results indicate that fungal growth increased with time, peaking at 4 days or 5 days. Higher relative humidity or temperature was conducive to fungal growth. The orthogonal experiment revealed that the condition of "antibacterial composite, $22 \pm 1^{\circ} \mathrm{C}$ and $45 \%-55 \% \mathrm{RH}^{\prime \prime}$ had the strongest inhibiting impact on fungal growth. Logistic model, Gompertz model and square-root model were further developed to predict the fungal growth under different conditions. The results show that the Logistic model had high feasibility and accuracy, the Gompertz model was feasible with lower accuracy and the square-root model was feasible with high accuracy. Overall, this study facilitates the understanding of the DAF growth in air-conditioning ducts, which is important for real-time prediction and timely control of the fungal contamination.
\end{abstract}

\section{Keywords}

dust accumulated fungi, high-throughput sequencing, air supply duct, duct material, orthogonal experiment, fungal growth prediction

\author{
Article History \\ Received: 10 May 2020 \\ Revised: 04 July 2020 \\ Accepted: 16 July 2020 \\ (c) Tsinghua University Press and \\ Springer-Verlag GmbH Germany, \\ part of Springer Nature 2020
}

\section{Introduction}

The outbreak of coronavirus (COVID-19), as well as previous pandemic diseases (i.e. SARS, MERS), has resulted in the deadliest losses to human society. To cut off the virus transmission path, many countries have taken isolation or quarantine measures. Residents must stay the indoors and the creation of comfortable, healthy and livable indoor environments is essential. Air-conditioning (AC) system is important in optimizing indoor environments by regulating air temperature, humidity and airflow and in eliminating indoor pollution by providing fresh and clean air (Seppänen 2008). However, many modern buildings are undergoing a rising indoor infection caused by air microorganisms (Qudiesat et al. 2009). The causes lie in a set of processes including airtightness increase, natural ventilation rate reduction, AC reliance increase, and microorganism accumulation and circulation (Satish et al. 2012; Maddalena et al. 2015). For instance, the contaminants within the AC system can circulate 5-7 times each day (Bakó-Biró et al. 2004).

This problem leads to worsened indoor air quality and thereby risks and threats to occupants' health, wellbeing and productivity. For instance, compared with naturally ventilated buildings, the occurrence of sick building syndrome (SBS) symptoms in air-conditioned buildings can increase by 30\%-200\% (Seppänen and Fisk 2002). The morbidity of

E-mail: zhijianliu@ncepu.edu.cn (Zhijian Liu); baojie.he@unsw.edu.au (Bao-Jie He) 
multi-chemical allergy and other illnesses are higher in airconditioned buildings (Bluyssen et al. 2003; Mendell et al. 2006; Gupta et al. 2007). The exposure to airborne fungi may further lead to allergic sensitization and respiratory symptoms, such as cough, phlegm, wheezing, sore throat and runny nose (Belanger et al. 2003; Mendell et al. 2011). As such, there is an urgent need for how to design and maintain AC systems properly to avoid contaminant pollution.

Solutions have been explored in terms of ventilation mode and dust control. Seppänen and Fisk (2002) and Batterman and Burge (1995) summarized the AC ventilation (ACV) modes related to human response and emphasized the proper design, operation and maintenance. However, Liu et al. (2015) pointed out that despite dust loading control, bacterial and fungal loadings in air supply segment were potential to exceed the critical value. It is essential to explore the contaminant microbial community distribution and growth within the ACV system. When the excessive contaminant particles resuspend, harmful substances in public buildings are capable of entering more rooms and more people are exposed to them via the intricate ACV duct networks (Li et al. 2012a). AC components, such as filters, heat exchangers, cooling coils, humidifiers and ducts, are direct or indirect sources of bacteria and fungi (Noris et al. 2009; Meng et al. 2015; Liu et al. 2017; Liu et al. 2018) and that of fungal colonization and amplification (Price et al. 1994; Batterman and Burge 1995).

These components, especially the ones with high humidity, provide nutrients and water for bacteria and fungi growth (Liu et al. 2019). Other factors (e.g. temperature, air re-circulation, wet material) can also promote microorganism growth (Chang et al. 1996; Noris et al. 2009). For instance, Bluyssen et al. (2003) pointed out that the microbial pollution source was mainly from the air filter and air duct and Wilson et al. (2007) concluded that the Cladosporium mainly grew on fan impeller, duct and cooling coil fin. Liu et al. (2005) contrasted microbes before and after air duct cleaning and pointed out that air duct was a critical component of microbial pollution. Lu et al. (2007) concluded that air supply ducts and equipment were vital for microorganism growth, on which basis they might spread downstream to the indoors.

To constrain microbial contamination, studies have investigated microorganism growth concerning temperature, relative humidity and supply air velocity of the ACV system. $\mathrm{Li}$ et al. (2010) found that the microorganism growth was accelerated with both increases in temperature and relative humidity, while air velocity attenuation affected dust distribution at the duct bottom where the microorganism number was positively correlated with dust quantity. Chang et al. (1996) pointed out that fungal growth could be affected by duct materials (e.g. fibrous glass board, galvanized steel, insulated flexible duct).

Studies have also analyzed microorganism growth variability with microorganism species. Liu et al. (2019) investigated fungi cultivability in five main HVAC segments of office buildings, concluding that the dominant culturable fungi were Penicillium, Aspergillus, Cladosporium and Alternaria with the occurrence rate of $75 \%$ and the culturable fungi were positively correlated with temperature. Li et al. (2012b) pointed out that the detective fungi included Penicillium, Aspergillus, Cladosporium, Alternaria, Mucor and Trichoderma with the proportions of $30.1 \%, 17.2 \%, 41.8 \% .5 .6 \%, 2.8 \%$, $0.5 \%$, respectively.

However, most previous studies on indoor biology have relied on culturable microorganisms which only account for a small part of the indoor microorganisms (Toivola et al. 2002). Several studies have adopted culture-independent, DNA-based approaches to better characterize the bacterial and fungal communities indoors (Kelley et al. 2004; Pakarinen et al. 2008; Rintala et al. 2008). Through molecular biology tools, Pitkäranta et al. (2008) found that there was a larger proportion of the microbial community than that of culturable methods. This result indicates that the threats caused by fungi accumulation to air supply quality was often recessive and more microbial particles were deposited in deeper parts of ducts (Zhu 2009). Due to this, there is a lack of in-depth analysis of the DAF pollution process and distribution characteristics in ACV ducts as well as the impact of ACV conditions on fungal growth. Moreover, the research on the viable fungi and fungal spores in ACV ducts was still lacking, while the fungi identification in existing studies mostly depends on morphological identification approach, limiting the results at the genera level.

In view of above-mentioned problems, this study aims to in-depth understand the DAF growth and reproduction in ACV ducts. This study is achieved through field measurement, laboratory experiment and prediction modelling. A combination of molecular biology in field measurement with the culturing and counting method in laboratory experiment is used to explore fungal species and fungi growth in ACV ducts. The fungal growth prediction models respecting various ACV conditions were developed to provide references for real-time prediction and the timely control of fungal contamination in ACV ducts.

\section{Methods and materials}

\subsection{Field measurement and molecular biology}

Field measurement was conducted in two rooms including an auditorium (A) and a VIP room (B) equipped with independent central AC systems (Table 1) on 11 April 2019. The AC systems were mainly operated for cooling purposes. 
Table 1 The parameters of the air handling unit.

\begin{tabular}{llll}
\hline \multicolumn{1}{c}{ Central AC System in Room A (AHU-A) } & \multicolumn{1}{c}{ Central AC System in Room B (AHU-B) } \\
\hline Rated cooling capacity $(\mathrm{kW})$ & 227 & Rated cooling capacity $(\mathrm{kW})$ & 70 \\
Rated air volume $\left(\mathrm{m}^{3} / \mathrm{h}\right)$ & 36000 & Rated air volume $\left(\mathrm{m}^{3} / \mathrm{h}\right)$ & 9000 \\
Motor power $(\mathrm{kW})$ & 11 & Motor power $(\mathrm{kW})$ & 4 \\
Full pressure $(\mathrm{Pa})$ & 490 & Exhaust volume $\left(\mathrm{m}^{3} / \mathrm{h}\right)$ & 9000 \\
Unit power supply & $380 \mathrm{~V} 3 \mathrm{PH} 50 \mathrm{~Hz}$ & Residual pressure $(\mathrm{Pa})$ & 400 \\
\hline
\end{tabular}

Air handling units (AHUs) in two rooms had the same structures, namely the simple primary return air system (Table 1). They were composed of air supply, filter, humidification, surface cooling and fan segments. Before the measurement, all segments except for the filter screen were cleaned to assess the cleaning effect.

Dust was sampled via manual wiping according to ACV hygienic specification (MOH 2012a). The sampling segments were filter screen, surface cooler and air supply duct surface in each ACV system for detecting dust volume and the total DAF number. Each section included three sampling points (i.e. top surface, bottom surface and side surface) and the area of each sampling point was $100 \mathrm{~cm}^{2}$. The manual wiping was conducted with the use of non-woven fabric and dust sampling frame to wipe all dust accumulated at sampling points. A specific procedure was to wear disposable plastic gloves, take $100 \mathrm{~mm} \times 100 \mathrm{~mm}$ non-woven and presterilized fabric by tweezers, collect dust and then weigh dust volume. The dust volume was weighed to calculate air duct pollution degree (unit: $\mathrm{g} / \mathrm{m}^{2}$ ), through dividing dust weight by the area of sampling point $\left(100 \mathrm{~cm}^{2}\right)$. Afterwards, dust samples were sealed in a sterile wild-mouth bottle (Zhou and Gao 2000; Xu 2013) and stored at room temperature in dark.

Then, the DAF number was measured. Under sterile operation condition, dust samples on the non-woven fabric were dissolved in $100 \mathrm{~mL}$ of $0.01 \%$ Tween- 80 by handshaking. Following this, $1 \mathrm{~mL}$ of the solution was taken three times with pipette and diluted in steps of 10 times $\left(10^{-1}, 10^{-2}, 10^{-3}\right)$. The diluent was respectively inoculated into the sterilizing cell-culture dish (two-day pre-cultivation without culture medium was conducted to ensure the cell-culture dishes were not polluted by other colonies ( $\mathrm{Yu}$ and Che 1998)) by pouring method, and three parallel samples were taken for each dilution. After the agar (Sabouraud medium) solidified, the plates were inverted and numbered. The DAF number of was recorded after three-day cultivation and after five-day cultivation to calculate the mean number of fungal colonies ( $n, \mathrm{CFU})$. On this basis, the total DAF number was obtained through the following formula:

$N=\frac{n K}{M}$ where $N(\mathrm{CFU} / \mathrm{g})$ is the total DAF number, $K$ is the dilution multiple, $M(\mathrm{~g})$ is the dust weight.

To further understand the community composition, DAF species and proportion were analyzed through highthroughput sequencing. The MiSeq method was used to sequence the fungal genome due to its advantages of high accuracy, high flux, fast sequencing speed and easy operation (Wang 2016). In particular, the fungal genome in sampling segments of AHU-A (including air supply duct 1 (SF1), air supply duct 2 (SF2), surface cooler (HR1) and filter screen (GL1)) and that of AHU-B (air supply duct (SF3), surface cooler (HR2) and filter screen (GL2)) were sequenced.

\subsection{Laboratory experimental test}

Laboratory experiment was conducted to analyze the impact of airflow parameter (e.g. temperature, relative humidity), growth time duration and duct material on DAF growth and reproduction. Orthogonal experiments were further conducted to compare the impact of above-mentioned factors, through which, it is expected to understand the optimal environmental conditions for inhibiting DAF growth and reproduction. The laboratory experiment was specifically conducted in a controllable air-conditioning duct (Figure 1, Appendix).

ACV ducts were required to work under various temperature and relative humidity to meet different indoor environmental requirements. Several air-conditioning working conditions in Table 2 were, therefore, considered, where the temperature and relative humidity were changeable, while the supply air velocity was at a conventional value of $3.0 \mathrm{~m} / \mathrm{s}$.

In addition, the impact of duct material was examined by changing the two test sections in straight ducts, as shown in Figure 1. The section in Straight duct 1 was made of antibacterial composite (Material 1) and the section in Straight duct 2 was made of galvanized iron sheet (Material 2).

Moreover, two test sections were respectively divided into 12 sampling points and they were numbered from (0) to (11), as shown in Figure 1. Each sampling point had a size of $10 \mathrm{~cm} \times 10 \mathrm{~cm}$. To analyze the impact of growth duration on DAF growth and reproduction, therefore, the 


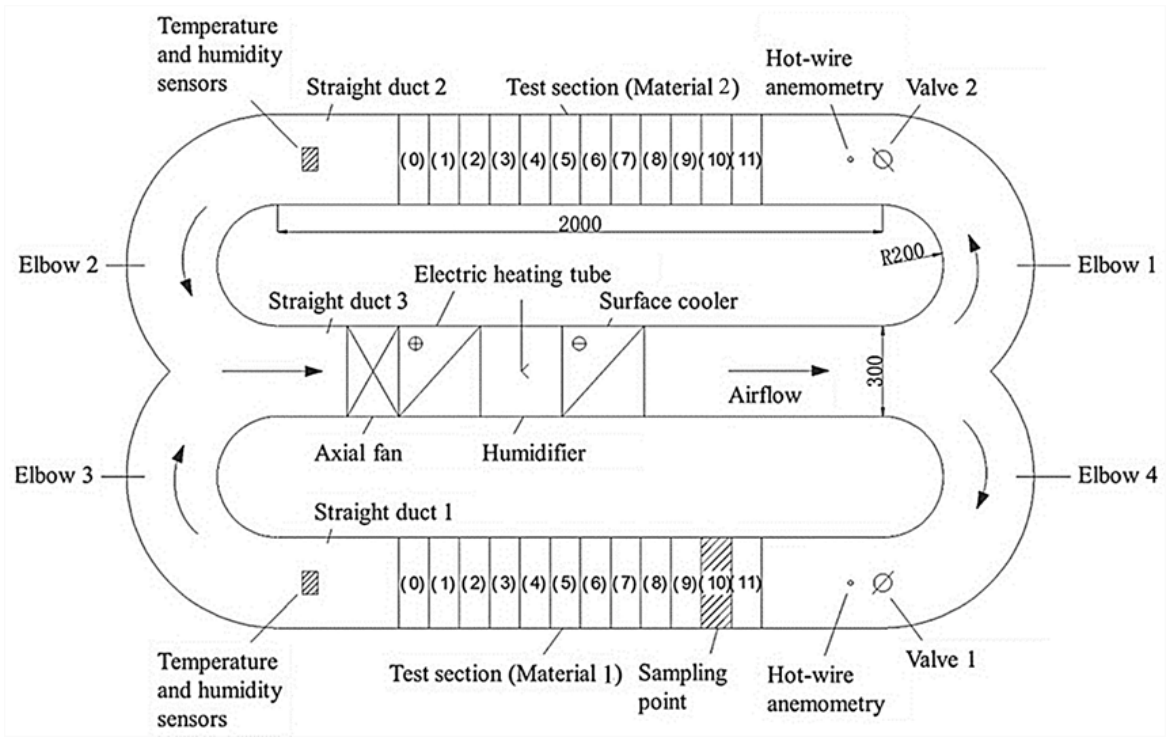

Fig. 1 Layout and components of the controllable air-conditioning duct

sampling time of 12 sampling points under each working condition (Table 2) was divided into six types and once a day (Table 3). The points (0)(11) were sampled without any preservation, only after 10 min of the time when original dust was placed into the air duct, to set $(0)(11)$ as the reference. The points (5)(6) were sampled on the sixth day after fiveday preservation. In addition, sampling was conducted after closing the test facility for 5 min every time.

Table 2 Experimental parameters of different working conditions.

\begin{tabular}{ccc}
\hline Working condition & Temperature $\left({ }^{\circ} \mathrm{C}\right)$ & RH $(\%)$ \\
\hline 1 & $22 \pm 1$ & $45-55$ \\
2 & $22 \pm 1$ & $60-70$ \\
3 & $22 \pm 1$ & $75-85$ \\
\hline 4 & $27 \pm 1$ & $45-55$ \\
5 & $27 \pm 1$ & $60-70$ \\
6 & $27 \pm 1$ & $75-85$ \\
\hline 7 & $32 \pm 1$ & $45-55$ \\
8 & $32 \pm 1$ & $60-70$ \\
9 & $32 \pm 1$ & $75-85$ \\
\hline
\end{tabular}

Table 3 Sampling sequence, preservation time and sampling locations

\begin{tabular}{ccc}
\hline Sequence & Preservation time $(\mathrm{d})$ & Location \\
\hline 1 & 0 & $(0)(11)$ \\
2 & 1 & $(1)(10)$ \\
3 & 2 & $(2)(9)$ \\
4 & 3 & $(3)(8)$ \\
5 & 4 & $(4)(7)$ \\
6 & 5 & $(5)(6)$ \\
\hline
\end{tabular}

After sampling, the measurement of DAF number was similar to the procedure followed in Section 2.1, including a two-day pre-cultivation of the cell-culture dish without culture medium, sample dilution in $100 \mathrm{~mL}$ of $0.01 \%$ Tween- 80 by handshaking, $1 \mathrm{~mL}$ solution dilution in $100 \mathrm{~mL}$ distilled water $\left(10^{-2}\right)$, the cultivation in the cell-culture dish with Sabouraud medium at $28{ }^{\circ} \mathrm{C}$ and with three parallel samples. Afterwards, the DAF number was respectively measured after three-day and five-day cultivation to calculate mean DAF number. Finally, the total DAF number can be obtained according to Eq. (1).

During the experimental fungi culture process, fungal colony characteristics were observed, where the morphology and color of the fungi colonies were observed by naked eyes. The fungal colonies that had been growing for 3-4 days were further selected by the inoculation loop and made into specimens for microscope observation. The results obtained by the observation can be validated by the high-throughput sequencing.

Orthogonal experiment (Table 4) was adopted to compare

Table 4 Orthogonal experimental design considering temperature, relative humidity, duct material and time.

\begin{tabular}{|c|c|c|c|c|}
\hline & A & B & C & $\mathrm{D}$ \\
\hline Factor & Duct material & $\begin{array}{c}\text { Relative } \\
\text { humidity (\%) }\end{array}$ & $\begin{array}{c}\text { Temperature } \\
\left({ }^{\circ} \mathrm{C}\right)\end{array}$ & $\begin{array}{c}\text { Time } \\
\text { (h) }\end{array}$ \\
\hline 1 & $\begin{array}{l}\text { Antibacterial } \\
\text { composite }\end{array}$ & $45-55$ & $21 \pm 1$ & 24 \\
\hline 2 & $\begin{array}{c}\text { Galvanized iron } \\
\text { sheet }\end{array}$ & $60-70$ & $27 \pm 1$ & 72 \\
\hline 3 & $\begin{array}{c}\text { Galvanized iron } \\
\text { sheet }\end{array}$ & $75-85$ & $31 \pm 1$ & 96 \\
\hline
\end{tabular}


the impact of temperature, relative humidity, duct material and growth time on DAF growth and reproduction, as well as to explore their interacting impacts. The duct material was a two-level factor and the rest were three-level factors.

To avoid the intervention of other sources, the air-conditioning duct was sanitized before all experiments. $75 \%$ medical alcohol was used to cleanse and sterilize duct walls, after which ducts were sterilized under an ultraviolet lamp for $30 \mathrm{~min}$ (Kanaan et al. 2016), and then air ducts were sealed. Furthermore, a pre-experiment was conducted to examine if the supply air velocity, temperature and relative humidity could meet experimental requirements under different working conditions, where $1 \mathrm{~g}$ of original dust sample was uniformly placed at each sampling location. The pre-experiment indicated that nutrients required by DAF growth could be met through placing Sabouraud medium on the duct. After the pre-experiment, the ducts were re-cleansed and disinfected for all subsequent experiments.

\subsection{Prediction model of fungal growth}

Predictive microbiology is becoming important to predict fungal growth and assess the impact of different factors on microorganisms (McMeekin et al. 2002; Oladokun et al. 2017). The predictive models include one-level, two-level and three-level models (Whiting and Buchanan 1993), where the one-level model describes the relationship between microorganism number and growth time, the two-level model presents how environmental factors affect parameters in the one-level model and the three-level model integrates the one-level and two-level model into computer software (McDonald and Sun 1999). In this study, one-level model and two-level model were used to predict DAF growth and the fungal contamination degree in ACV ducts in real-time.

The Logistic model and Gompertz model, in the one-level model, were adopted to predict DAF growth in ACV ducts. The expression of the Logistic model is given in Eq. (2) (Gibson et al. 1987):

$\lg \left(N_{t}\right)=A+\frac{C}{1+\mathrm{e}^{(-B(t-M))}}$

where $N_{\mathrm{t}}(\mathrm{CFU} / \mathrm{g})$ is the number of microorganisms at a specific time $t(\mathrm{~h}), A(\log (\mathrm{CFU} / \mathrm{g}))$ is the logarithm of the initial microbial quantity, $C(\log (\mathrm{CFU} / \mathrm{g}))$ is the asymptotic growth of microorganisms when the time $t$ approaches infinity, namely the difference between the maximum colony pair value and the initial quantity pair value, $M(\mathrm{~h})$ is the time to reach the relative maximum growth rate, $B\left(\mathrm{~h}^{-1}\right)$ is the relative maximum growth rate at the time $M$.
The expression of the Gompertz model is given in Eq. (3) (Gibson et al. 1987):

$\lg \left(N_{t}\right)=A+C \mathrm{e}^{-\mathrm{e}^{(-B(t-M))}}$

where all parameters have the same meanings as that in Eq. (2).

Square-Root model (SRM), in the two-level models, was adopted to estimate ADF growth of dust accumulated fungi in ACV ducts (Ratkowsky et al. 1982). It is expressed as follows:

$\sqrt{\mathrm{GR}}=b\left(T-T_{\min }\right)$

where GR $\left(\mathrm{h}^{-1}\right)$ is the maximum growth rate, $b$ is the regression coefficient, $T_{\min }\left({ }^{\circ} \mathrm{C}\right)$ is the theoretical minimum temperature of microbial growth, which is the most important parameter of the SRM and the $T_{\min }$ of zero birth rate is obtained by extrapolation of the SRM.

Although SRM is simple and can well predict microorganism growth under an individual factor (Ratkowsky et al. 1982), its results may be inaccurate when microbial growth is subjected to multiple factors. Therefore, McMeekin et al. (1987) proposed a modified SRM under the combining impact of temperature and relative humidity. The modified equation is expressed as follows.

$\sqrt{\mathrm{GR}}=b\left(T-T_{\min }\right) \sqrt{\varphi-\varphi_{\min }}$

where $\varphi(\%)$ is the experimental relative humidity condition, $\varphi_{\min }(\%)$ is the relative humidity value when the growth rate is 0 . Other parameters have the same meaning as Eq. (4).

Furthermore, the feasibility and accuracy of predictive models were tested, where the bias factor $B_{\mathrm{f}}$ and accuracy factor $A_{\mathrm{f}}$ were chosen as the assessment indicators. When the $B_{\mathrm{f}}$ value falls into $0.70-0.90$ or $1.05-1.15$, the model is acceptable; when the $B_{\mathrm{f}}$ value is $0.90-1.05$, the model has good applicability; when the $B_{\mathrm{f}}$ value is $\leq 0.70$ or $\geq 1.15$, the model is unacceptable (Ross 1996). Nevertheless, the model accuracy cannot be fully assessed by $B_{\mathrm{f}}$ and the accuracy factor $A_{\mathrm{f}}$ is introduced to further test models. If the value of $A_{\mathrm{f}}$ is larger, the accuracy of models is lower; if $A_{\mathrm{f}}=1$, all predicted values of models are equal to the observed values. The bias factor $B_{\mathrm{f}}$ and the accuracy factor $A_{\mathrm{f}}$ can be calculated as follows:

$B_{\mathrm{f}}=10^{\sum \frac{\lg \left(N_{\text {predicted }} / N_{\text {observed }}\right)}{n}}$
$A_{\mathrm{f}}=10^{\sum \frac{\left|\lg \left(N_{\text {predicted }} / N_{\text {observed }}\right)\right|}{n}}$

where $N_{\text {predicted }}(\mathrm{CFU} / \mathrm{g})$ is the predicted DAF value obtained by models, $N_{\text {observed }}(\mathrm{CFU} / \mathrm{g})$ is the measured DAF colonies by experiments, $\mathrm{n}$ is the number of measurement. 


\section{Results and discussion}

3.1 Fungal pollution and microbial structures in ACV ducts

Through field measurement and molecular biology, dust volume, fungal concentration as well as the DAF community composition, structure and diversity in ACV ducts was obtained.

\subsubsection{Dust volume, fungal concentration and cleansing effect}

Table 5 presents the dust volume and fungal concentration in AHU-A and AHU-B.

The mean dust volume at each sampling point was: $14.9 \mathrm{~g} / \mathrm{m}^{2}, 11.9 \mathrm{~g} / \mathrm{m}^{2}, 3.0 \mathrm{~g} / \mathrm{m}^{2}, 7.6 \mathrm{~g} / \mathrm{m}^{2}, 11.2 \mathrm{~g} / \mathrm{m}^{2}, 50.3 \mathrm{~g} / \mathrm{m}^{2}$ and $1.1 \mathrm{~g} / \mathrm{m}^{2}$, while the DAF concentration at each sampling point was $9.6 \mathrm{CFU} / \mathrm{cm}^{2}, 6.9 \mathrm{CFU} / \mathrm{cm}^{2}, 0.8 \mathrm{CFU} / \mathrm{cm}^{2}$, $3.1 \mathrm{CFU} / \mathrm{cm}^{2}, 5.2 \mathrm{CFU} / \mathrm{cm}^{2}, 43.8 \mathrm{CFU} / \mathrm{cm}^{2}$ and $0.3 \mathrm{CFU} / \mathrm{cm}^{2}$, respectively. This means the measured results could generally meet the specified requirements (the thresholds of dust on the inner surface and the total number of fungi are $20 \mathrm{~g} / \mathrm{m}^{2}$ and $100 \mathrm{CFU} / \mathrm{cm}^{2}$, respectively) (MOH 2012a), except for the filter screen of air handling unit $\mathrm{A}$.

Moreover, the residual dust, after cleansing and disinfection, on the inner surface of ACV duct should be less than $1 \mathrm{~g} / \mathrm{m}^{2}$ and the total fungi on the inner surface of
ACV duct and air-conditioning components should be less than $100 \mathrm{CFU} / \mathrm{m}^{2}$ (MOH 2012b). The results show that DAF concentration at each sampling point was much higher than the standard thresholds, indicating the cleansing effect was not good, which may lead to secondary pollution. Therefore, it is essential to improve the cleansing efficiency or increase cleansing times.

\subsubsection{Fungal community composition, structure and microbial diversity}

The results obtained by Miseq sequence are presented in Table 6. According to the similarity, all sample sequences were clustered and divided into different operational taxonomic unit (OTU) that refers to the same mark set artificially for each taxon.

In general, the OTUs at $97 \%$ similarity level was used for the statistical analysis of biological information. Venn diagram could be used to count the number of common and unique OTUs in the samples, and intuitively showed the similarity and overlap of the number of OTUs in the samples, as shown in Figure 2. In the four sampling segments of AHU-A (Figure 2(a)), the overlap number of the OUTs of SF1 with that of HR1, GL1 and SF2 were 30, 90 and 62 respectively, indicating that SF1 and GL1 had the highest species similarity. The number of OTUs overlap among all four parts was 15 .

Table 5 Dust volume and fungal concentration of air-conditioning system after cleansing.

\begin{tabular}{|c|c|c|c|c|c|c|c|c|}
\hline \multirow[b]{2}{*}{ Sampling point } & \multirow{2}{*}{$\begin{array}{l}\text { No. of sealing } \\
\text { bag }\end{array}$} & \multirow{2}{*}{$\begin{array}{l}\text { Primary } \\
\text { value }(g)\end{array}$} & \multirow{2}{*}{$\begin{array}{c}\text { Final value } \\
(\mathrm{g})\end{array}$} & \multirow{2}{*}{$\begin{array}{l}D \text {-value } \\
\quad(\mathrm{g})\end{array}$} & \multirow{2}{*}{$\begin{array}{l}\text { Dust volume } \\
\qquad\left(\mathrm{g} / \mathrm{m}^{2}\right)\end{array}$} & \multirow{2}{*}{$\begin{array}{c}\text { Mean dust } \\
\text { volume }\left(\mathrm{g} / \mathrm{m}^{2}\right)\end{array}$} & \multicolumn{2}{|c|}{ Mean value of total fungi } \\
\hline & & & & & & & $(\mathrm{CFU} / \mathrm{g})$ & $\left(\mathrm{CFU} / \mathrm{cm}^{2}\right)$ \\
\hline \multirow{3}{*}{ (A) Air supply duct 1} & 1 & 4.087 & 4.244 & 0.157 & 15.7 & \multirow{3}{*}{14.9} & \multirow{3}{*}{6400} & \multirow{3}{*}{9.6} \\
\hline & 2 & 4.033 & 4.295 & 0.262 & 26.2 & & & \\
\hline & 3 & 4.012 & 4.041 & 0.029 & 2.9 & & & \\
\hline \multirow{3}{*}{ (A) Air supply duct 2} & 4 & 4.035 & 4.162 & 0.127 & 12.7 & \multirow{3}{*}{11.9} & \multirow{3}{*}{5800} & \multirow{3}{*}{6.9} \\
\hline & 5 & 4.099 & 4.288 & 0.189 & 18.9 & & & \\
\hline & 6 & 4.091 & 4.133 & 0.042 & 4.2 & & & \\
\hline \multirow{3}{*}{ (B) Air supply duct } & 7 & 3.979 & 4.026 & 0.047 & 4.7 & \multirow{3}{*}{3.0} & \multirow{3}{*}{2600} & \multirow{3}{*}{0.8} \\
\hline & 8 & 3.956 & 3.989 & 0.033 & 3.3 & & & \\
\hline & 9 & 4.007 & 4.016 & 0.009 & 0.9 & & & \\
\hline \multirow{3}{*}{ (A) Surface cooler } & 10 & 4.096 & 4.191 & 0.095 & 9.5 & \multirow{3}{*}{7.6} & \multirow{3}{*}{4100} & \multirow{3}{*}{3.1} \\
\hline & 11 & 4.083 & 4.165 & 0.082 & 8.2 & & & \\
\hline & 12 & 4.101 & 4.153 & 0.052 & 5.2 & & & \\
\hline \multirow{3}{*}{ (B) Surface cooler } & 13 & 4.053 & 4.146 & 0.093 & 9.3 & \multirow{3}{*}{11.2} & \multirow{3}{*}{4600} & \multirow{3}{*}{5.2} \\
\hline & 14 & 4.07 & 4.216 & 0.146 & 14.6 & & & \\
\hline & 15 & 4.106 & 4.204 & 0.098 & 9.8 & & & \\
\hline (A) Filter screen & 16 & 2.948 & 3.451 & 0.503 & 50.3 & 50.3 & 8700 & 43.8 \\
\hline (B) Filter screen & 17 & 2.976 & 2.987 & 0.011 & 1.1 & 1.1 & 3000 & 0.3 \\
\hline
\end{tabular}

Note: (A) and (B) mean the air handling units in Room A and Room B, respectively 
Table 6 Statistics of sample data information.

\begin{tabular}{ccccc}
\hline Unit & Sample & $\begin{array}{c}\text { Barcode } \\
\text { sequence }\end{array}$ & $\begin{array}{c}\text { Sequence data after } \\
\text { quality control }\end{array}$ & $\begin{array}{c}\text { Mean sequence } \\
\text { length }\end{array}$ \\
\hline B & SF3 & AGTCGTC & 76610 & 232.98 \\
A & SF2 & AGAGCAG & 90188 & 228.69 \\
A & SF1 & AGCTCTA & 87109 & 231.45 \\
B & HR2 & AGTATAC & 92517 & 236.8 \\
A & HR1 & AGTGCGA & 99013 & 230.3 \\
B & GL2 & ACACACG & 101687 & 233.48 \\
A & GL1 & ACAGCGA & 99735 & 242.21 \\
\hline
\end{tabular}

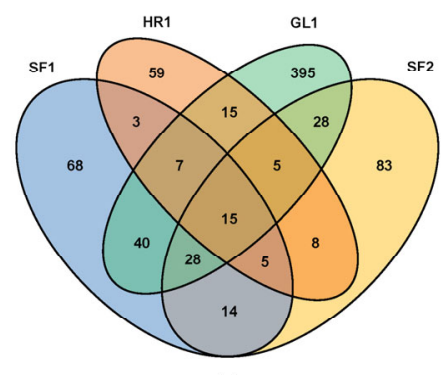

(a)

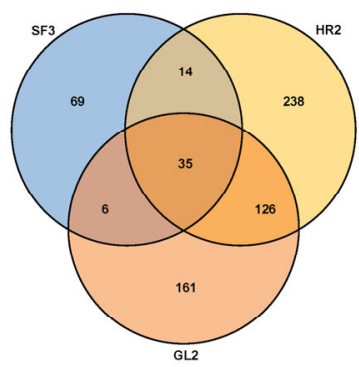

(b)

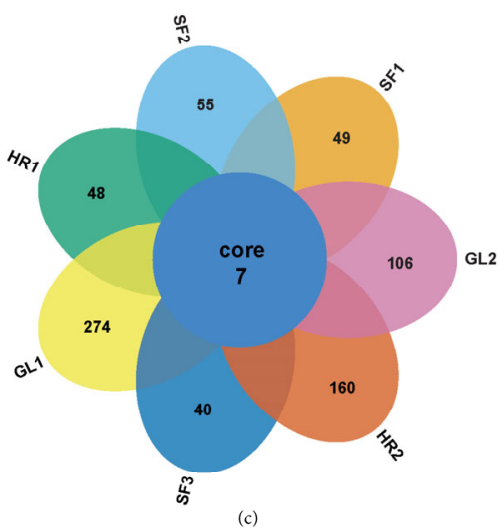

Fig. 2 Venn diagram: (a) OTU distribution of sampling points of AHU-A, (b) OTU distribution of sampling points of AHU-B and (c) OTUs distribution of all sampling points

In AHU-B (Figure 2(b)), the number of OTUs overlap among all three parts was 35, while the GL2 and HR2 had the highest similarity with the overlap value of 161 . According to Figure 2(c), the number of the OTUs intersection among all seven segments was 7 , indicating the sample overlap was not high. There were more OTUs in GL1 and GL2, indicating the fungal species composition on filter screens were more abundant.

The rank-abundance curve can be used to explain sample diversity in species richness and species evenness, where the species richness is analyzed by curve length along the horizontal axis: the longer the curve, the richer the species composition. The species evenness can be analyzed by curve shape: the flatter the curve, the higher the evenness of species composition. As shown in Figure 3, OTUs in each

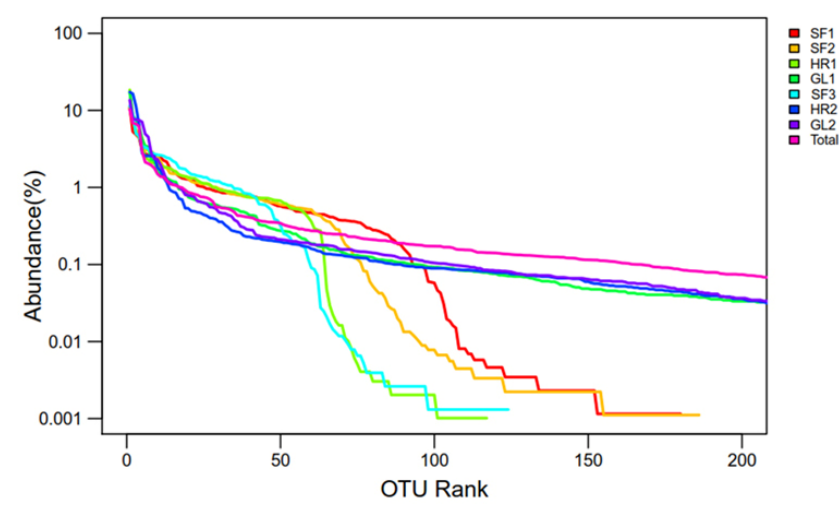

Fig. 3 Rank-abundance curves in terms of species richness and species evenness

sample was sorted by abundance (number of sequences contained) from large to small, then take the OUT rank as the abscissa and the abundance of each OTU as the ordinate. The curves of HR2, GL2 and GL1 were much longer, indicating that there were abundant fungal species in the filter screen segments of AHU-A and AHU-B and the surface cooler segment of AHU-B. In comparison, curves of HR1, SF1, SF2 and SF3 were steeper, indicating lower evenness of fungal species in the surface cooler segment of AHU-A and all air supply segment of AHU-A and AHU-B.

Figure 4 and Table 7 present the taxonomic composition of the fungal community, through which the community structure of the samples at the genus level can be observed. The dominant genera in AHU-A were Alternaria, Verticillium, Aspergillus, Cladosporium, Mortierella, etc. and that in AHU-B were Cladosporium, Alternaria, Aspergillus, Nothophoma, etc. Among them, the dominant genera in GL1, SF1, SF2 and HR1 of AHU-A were Alternaria, Alternaria, Mortierella and Verticillium, with the content of $17.6 \%, 11.03 \%, 14.79 \%$ and $18.72 \%$, respectively. The dominant genera of GL2, SF3 and HR2 of AHU-B were Nothophoma, Verticillium and Aspergillus, with the content of $15.33 \%, 11.46 \%$ and $20.01 \%$, respectively. Overall, the Alternaria, Cladosporium and Aspergillus were the dominant genera in both AHU-A and AHU-B.

However, some fungal genera were unclassified, which might be caused by the databases used (RDP database: http://rdp.cme.msu.edu/misc/resources.jsp; Unite database, http://unite.ut.ee/index.php) did not include their sequences or the taxonomic accuracy was limited.

Clustering tree and sample heatmap are presented in Figure 5. The samples were clustered in Figure 5: the more similar the sample community distribution, the closer the sample position in the clustering tree. The sample community distribution in HR2 and GL2, SF1 and SF2 were similar. The Alternaria, Cladosporium and Aspergillus were detected in all samples, all of which were dominant 


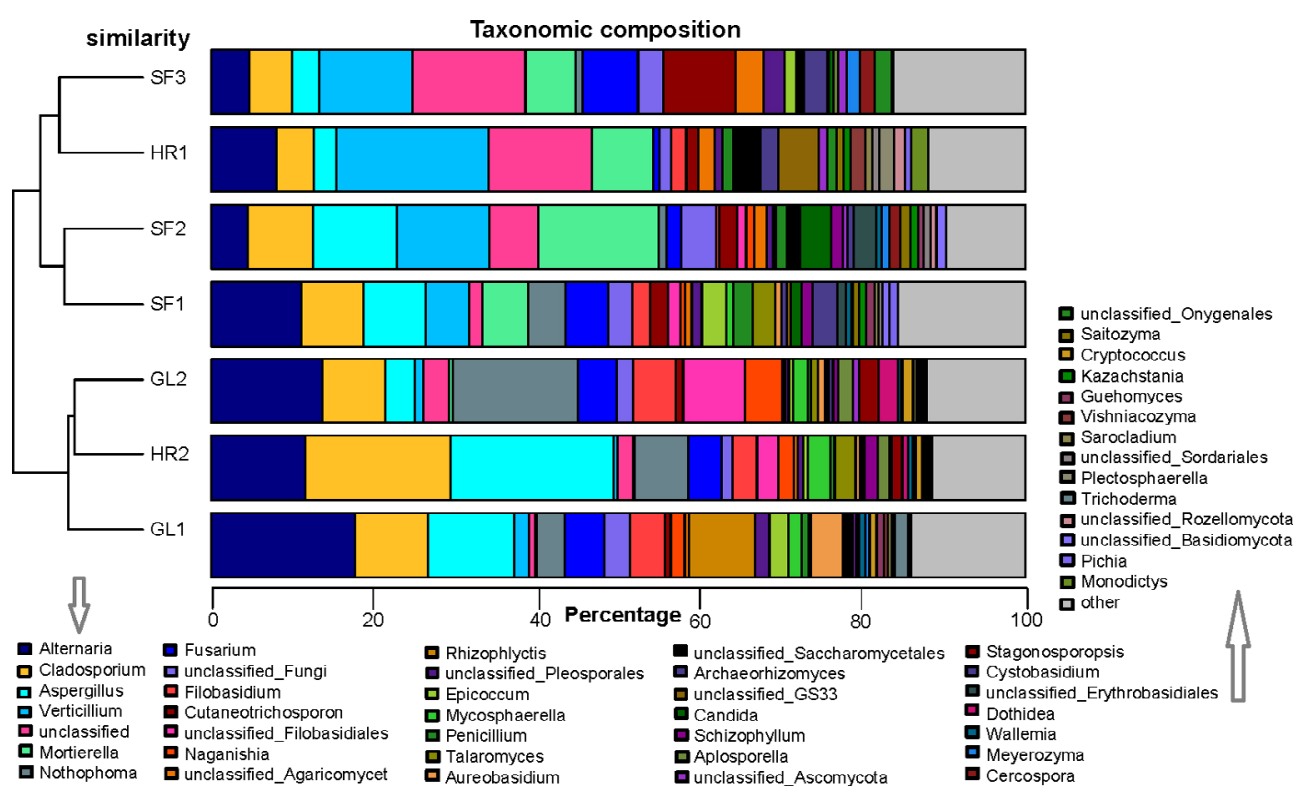

Fig. 4 Taxonomic composition distribution of samples at genus level

Table 7 Fungal composition of each sampling point (\%)

\begin{tabular}{|c|c|c|c|c|c|c|c|}
\hline \multirow[b]{2}{*}{ Genus } & \multicolumn{4}{|c|}{ AHU-A } & \multicolumn{3}{|c|}{ AHU-B } \\
\hline & GL1 & SF1 & SF2 & HR1 & GL2 & SF3 & HR2 \\
\hline Alternaria & 17.6 & 11.03 & 4.44 & 8 & 13.59 & 4.64 & 11.51 \\
\hline Cladosporium & 9.01 & 7.68 & 7.99 & 4.54 & 7.77 & 5.29 & 17.85 \\
\hline Aspergillus & 10.59 & 7.62 & 10.31 & 2.82 & 3.64 & 3.33 & 20.01 \\
\hline Verticillium & 1.79 & 5.31 & 11.37 & 18.72 & 1 & 11.46 & 0.55 \\
\hline Penicillium & 0.85 & 2.35 & 1.34 & 1.36 & 0.44 & - & 0.54 \\
\hline Mortierella & 0.16 & 5.6 & 14.79 & 7.51 & 0.52 & 6.17 & 0.19 \\
\hline Nothophoma & 3.48 & 4.61 & 0.99 & - & 15.33 & 0.82 & 6.63 \\
\hline Fusarium & 4.86 & 5.25 & 1.82 & 0.74 & 4.77 & 6.85 & 4.04 \\
\hline Filobasidium & 4.33 & 2.16 & 0.44 & 1.87 & 5.24 & 0 & 2.98 \\
\hline Cutaneotrichosporon & 0.62 & 2.24 & 2.17 & 1.47 & 0.94 & 8.86 & 0.08 \\
\hline unclassified_Filobasidiales & 0.14 & 1.51 & 1.11 & - & 7.58 & - & 2.57 \\
\hline Naganishia & 1.65 & 0.58 & 1.01 & - & 4.63 & - & 1.92 \\
\hline unclassified_Agaricomycetes & 0.55 & 0.81 & 1.54 & 2.02 & 0.37 & 3.44 & 0.5 \\
\hline unclassified & 0.8 & 1.64 & 6.04 & 12.68 & 3.13 & 13.85 & 1.85 \\
\hline Other & 43.57 & 41.61 & 34.64 & 38.27 & 31.05 & 35.29 & 28.78 \\
\hline
\end{tabular}

genera, while Penicillium was less, which is different from the results of other literature. In addition, the dominant species in all sampling segments were Alternaria_betaekenyensis, Cladosporium_delicatulum, Aspergillus_sydowii, Verticillium_dahliae.

3.2 Impact of different factors on the growth and reproduction of dust accumulated fungi

Figure 6 presents the variation of the total DAF number under different combination of relative humidity, temperature, time duration and duct material. On antibacterial composite (Figure 6(a)), with temperature and relative humidity ranges of $22-32{ }^{\circ} \mathrm{C}$ and $45 \%-85 \%$, the DAF number increased over time and peaked at 4 days or 5 days. Nevertheless, the fungal growth may exhibit some fluctuations in the early stage, where the number of fungi decreased slightly in two days and then increased until it reached its peak. Likewise, the DAF number on galvanized iron sheet increased with time (Figure 6(b)).

Compared with antibacterial composite, the DAF number on galvanized iron sheet was much higher and the DAF 


\section{heatmap of genus}

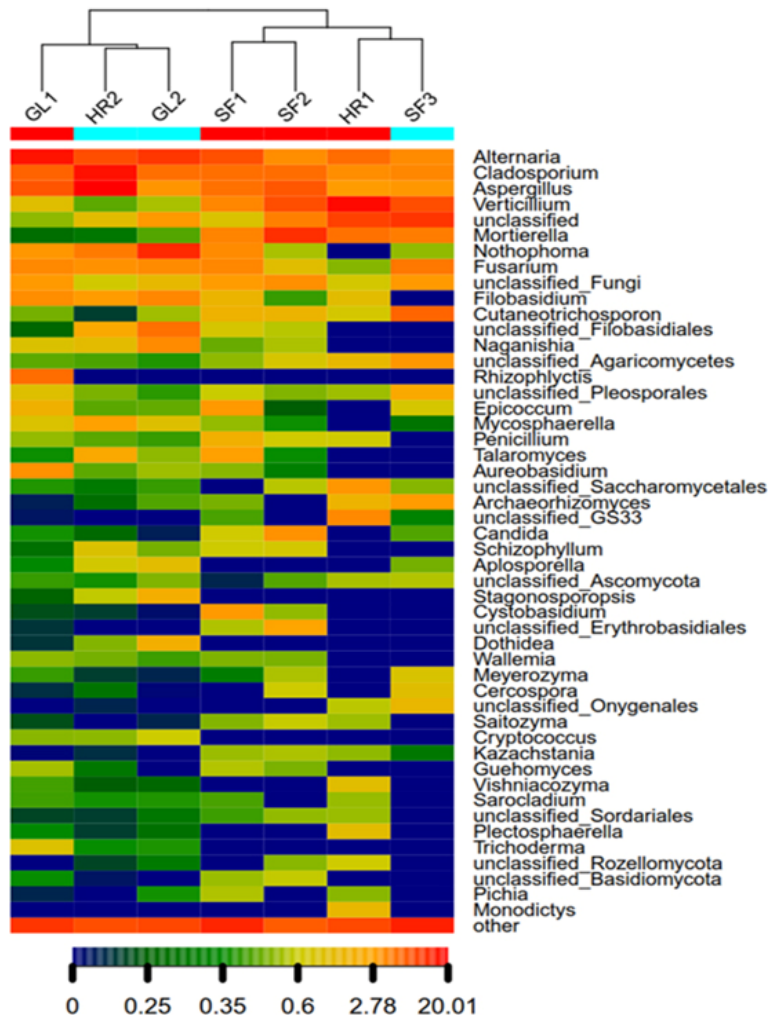

Fig. 5 Clustering tree and heatmap of samples at genus level

growth was faster. This result indicates that galvanized iron sheet was more suitable for DAF growth. Meanwhile, the number of fungal colonies generally peaked at 4 days, after which the growth rate became negative or decreased. In addition, the impact of relative humidity on antibacterial composite and galvanized iron sheet was also presented, where a higher relative humidity generally corresponded to a higher DAF number: high humidity $(75 \%-85 \%)>$ medium humidity $(60 \%-70 \%)>$ low humidity $(45 \%-55 \%)$.

Figure 7 presents variations in the total DAF number under different conditions. The results in Figure 7 were similar to that in Figure 6, where the total DAF number increased with time. Meanwhile, fungal growth on antibacterial composite peaked at 4 days or 5 days while that on galvanized iron generally peaked at 4 days. The galvanized iron sheet was more suitable for fungal growth in growth rate and number. For galvanized iron sheet (Figure 7(b)), a higher temperature corresponded to a higher DAF number: high temperature $\left(32 \pm 1{ }^{\circ} \mathrm{C}\right)>$ and medium temperature $\left(27 \pm 1^{\circ} \mathrm{C}\right)>$ and low humidity $\left(22 \pm 1^{\circ} \mathrm{C}\right)$. In addition, the number of fungal colonies on the galvanized iron sheet was significantly higher than that on antibacterial composite (Figure 8), indicating that galvanized iron sheet was more suitable for DAF growth.

The fungal colonies were further observed in laboratory experiment through a microscope to understand the fungal morphology, color and genera. Six types of fungi, including Alternaria, Aspergillus, Cladosporium, Penicillium, Rhizopus and Mucor, were observed in the experimental specimens and their morphology and color were given in Figure 9. Overall, fungi observed by microscope were consistent with that of high-throughput sequencing.

Table 8 and Table 9 present the results of orthogonal experiment analysis and variance analysis, respectively. The duct material had the greatest impact on DAF growth, followed by the growth time, relative humidity and temperature $(A>D>B>C)$. Moreover, duct material $(A)$, growth time (D), relative humidity (B), and the temperature and time interaction $(\mathrm{C} \times \mathrm{D})$ made extremely significant differences to fungal growth. In comparison, temperature (C), the duct material and time interaction $(A \times D)$, and the relative humidity and time interaction $(\mathrm{B} \times \mathrm{D})$ made significant
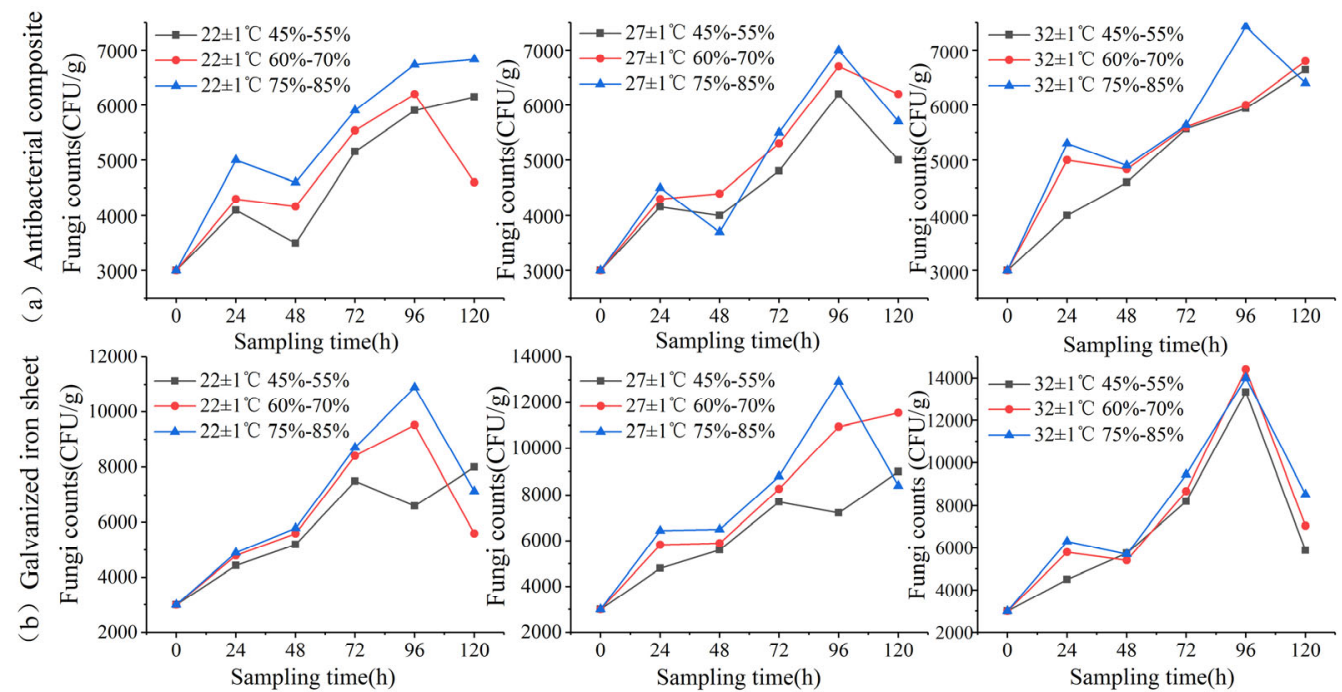

Fig. 6 Variation of the total DAF number with relative humidity 

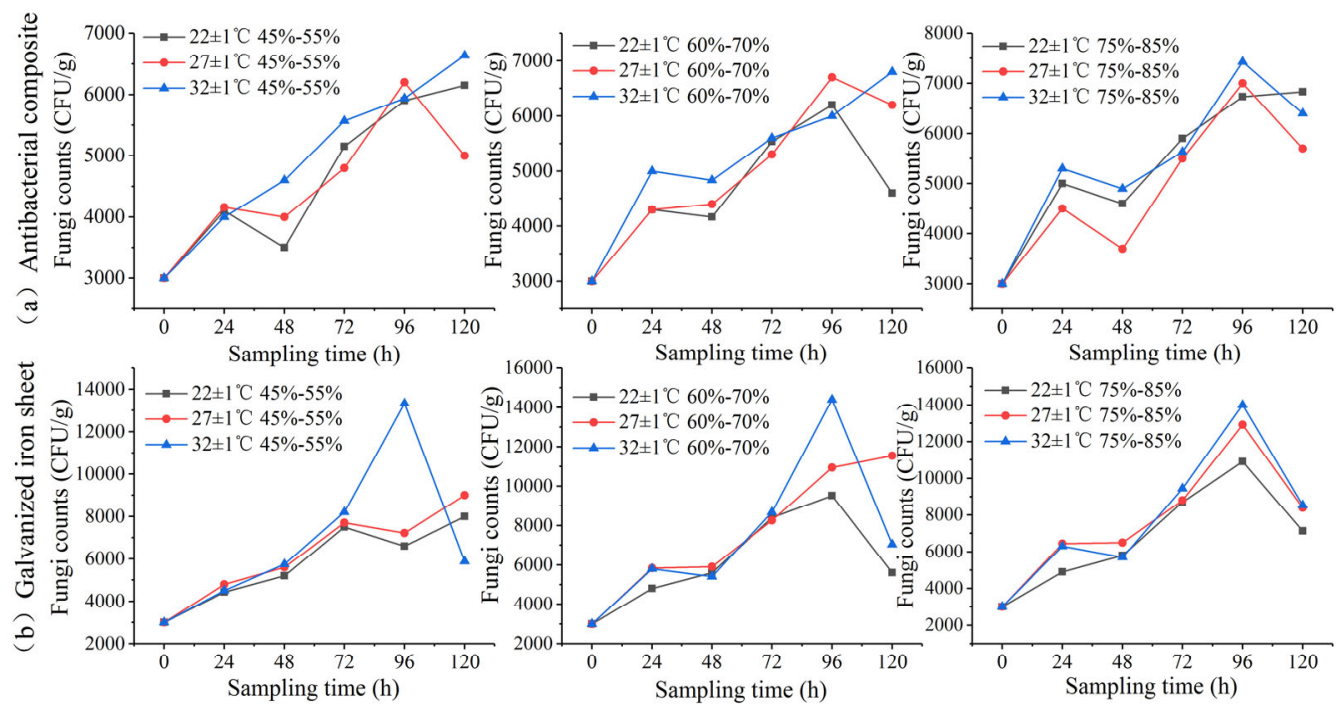

Fig. 7 Variation of the total DAF number with temperature

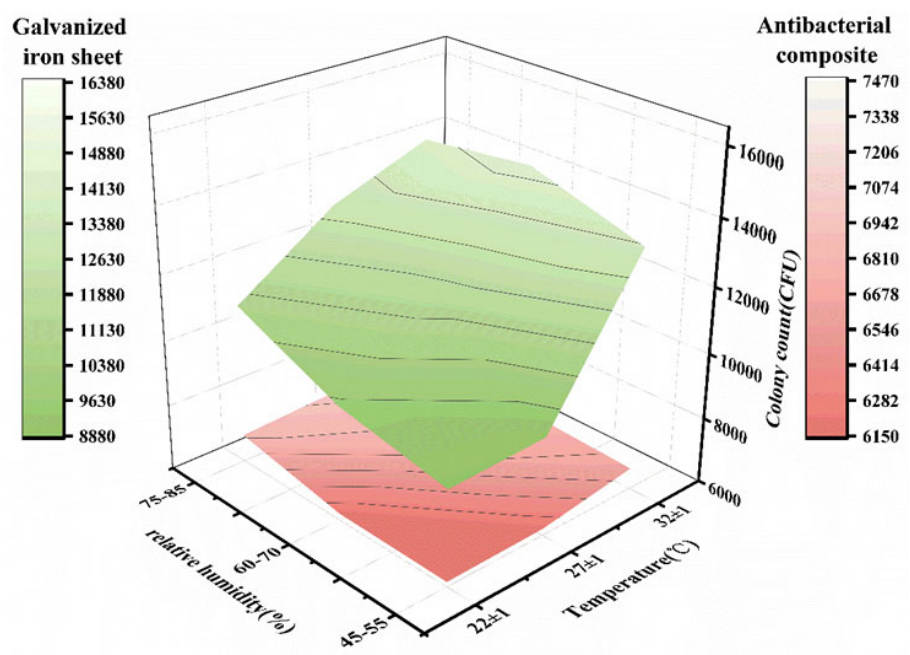

Fig. 8 Curved surfaces of fungi growth peak in different duct materials

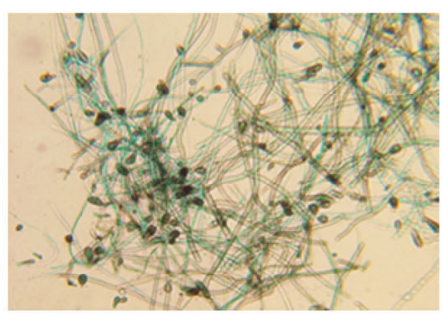

Alternaria

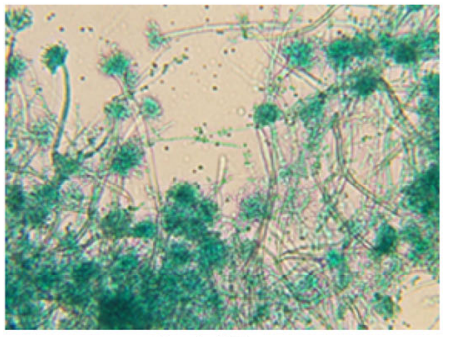

Penicillium

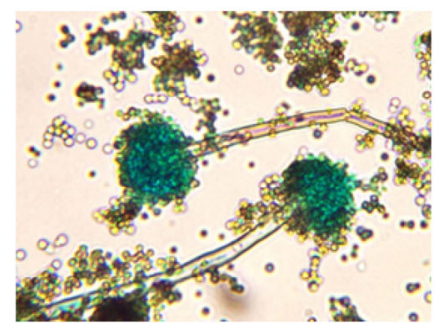

Aspergillus

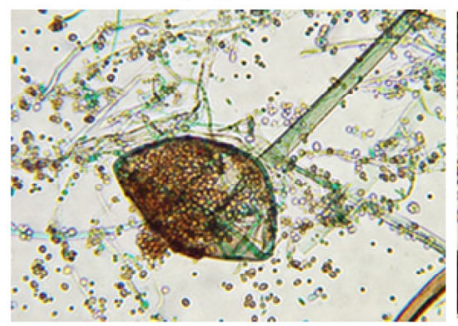

Rhizopus

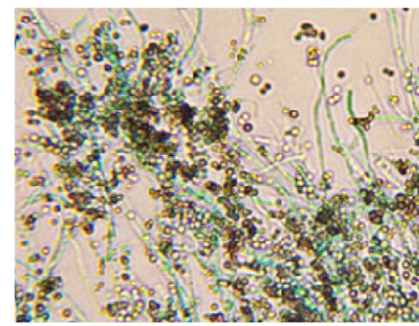

Cladosporium

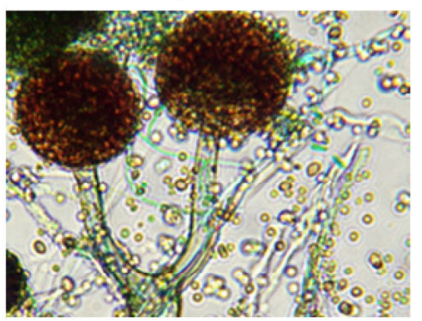

Mucor

Fig. 9 The morphology and color of six kinds of fungi observed by microscope 
Table $8 \quad \mathrm{~L}_{27}\left(3^{13}\right)$ Orthogonal experimental design results

\begin{tabular}{|c|c|c|c|c|c|c|c|c|c|c|c|c|c|c|}
\hline & A & B & $\mathrm{AB}_{1}$ & $\mathrm{AB}_{2}$ & C & $\mathrm{AC}_{1}$ & $\mathrm{AC}_{2}$ & $\begin{array}{l}\text { Empty } \\
\text { column }\end{array}$ & $\mathrm{D}$ & $\mathrm{AD}_{1}$ & $\begin{array}{l}\text { Empty } \\
\text { column }\end{array}$ & $\mathrm{BD}_{1}$ & $\mathrm{CD}_{1}$ & $\begin{array}{c}\text { Colony } \\
\text { count } \\
\left(10^{2} \mathrm{CFU}\right)\end{array}$ \\
\hline 1 & 1 & 1 & 1 & 1 & 1 & 1 & 1 & 1 & 1 & 1 & 1 & 1 & 1 & 41.0 \\
\hline 2 & 1 & 1 & 1 & 1 & 2 & 2 & 2 & 2 & 2 & 2 & 2 & 2 & 2 & 48.0 \\
\hline 3 & 1 & 1 & 1 & 1 & 3 & 3 & 3 & 3 & 3 & 3 & 3 & 3 & 3 & 59.4 \\
\hline 4 & 1 & 2 & 2 & 2 & 1 & 1 & 1 & 2 & 2 & 2 & 3 & 3 & 3 & 55.3 \\
\hline 5 & 1 & 2 & 2 & 2 & 2 & 2 & 2 & 3 & 3 & 3 & 1 & 1 & 1 & 67.0 \\
\hline 6 & 1 & 2 & 2 & 2 & 3 & 3 & 3 & 1 & 1 & 1 & 2 & 2 & 2 & 50.0 \\
\hline 7 & 1 & 3 & 3 & 3 & 1 & 1 & 1 & 3 & 3 & 3 & 2 & 2 & 2 & 67.3 \\
\hline 8 & 1 & 3 & 3 & 3 & 2 & 2 & 2 & 1 & 1 & 1 & 3 & 3 & 3 & 45.0 \\
\hline 9 & 1 & 3 & 3 & 3 & 3 & 3 & 3 & 2 & 2 & 2 & 1 & 1 & 1 & 56.3 \\
\hline 10 & 2 & 1 & 2 & 3 & 1 & 2 & 3 & 1 & 2 & 3 & 1 & 2 & 3 & 75.0 \\
\hline 11 & 2 & 1 & 2 & 3 & 2 & 3 & 1 & 2 & 3 & 1 & 2 & 3 & 1 & 72.2 \\
\hline 12 & 2 & 1 & 2 & 3 & 3 & 1 & 2 & 3 & 1 & 2 & 3 & 1 & 2 & 45.0 \\
\hline 13 & 2 & 2 & 3 & 1 & 1 & 2 & 3 & 2 & 3 & 1 & 3 & 1 & 2 & 95.2 \\
\hline 14 & 2 & 2 & 3 & 1 & 2 & 3 & 1 & 3 & 1 & 2 & 1 & 2 & 3 & 58.3 \\
\hline 15 & 2 & 2 & 3 & 1 & 3 & 1 & 2 & 1 & 2 & 3 & 2 & 3 & 1 & 86.8 \\
\hline 16 & 2 & 3 & 1 & 2 & 1 & 2 & 3 & 3 & 1 & 2 & 2 & 3 & 1 & 49.0 \\
\hline 17 & 2 & 3 & 1 & 2 & 2 & 3 & 1 & 1 & 2 & 3 & 3 & 1 & 2 & 88.0 \\
\hline 18 & 2 & 3 & 1 & 2 & 3 & 1 & 2 & 2 & 3 & 1 & 1 & 2 & 3 & 140.0 \\
\hline 19 & 2 & 1 & 3 & 2 & 1 & 3 & 2 & 1 & 3 & 2 & 1 & 3 & 2 & 66.0 \\
\hline 20 & 2 & 1 & 3 & 2 & 2 & 1 & 3 & 2 & 1 & 3 & 2 & 1 & 3 & 48.0 \\
\hline 21 & 2 & 1 & 3 & 2 & 3 & 2 & 1 & 3 & 2 & 1 & 3 & 2 & 1 & 82.0 \\
\hline 22 & 2 & 2 & 1 & 3 & 1 & 3 & 2 & 2 & 1 & 3 & 3 & 2 & 1 & 48.0 \\
\hline 23 & 2 & 2 & 1 & 3 & 2 & 1 & 3 & 3 & 2 & 1 & 1 & 3 & 2 & 82.6 \\
\hline 24 & 2 & 2 & 1 & 3 & 3 & 2 & 1 & 1 & 3 & 2 & 2 & 1 & 3 & 144.0 \\
\hline 25 & 2 & 3 & 2 & 1 & 1 & 3 & 2 & 3 & 2 & 1 & 2 & 1 & 3 & 87.0 \\
\hline 26 & 2 & 3 & 2 & 1 & 2 & 1 & 3 & 1 & 3 & 2 & 3 & 2 & 1 & 129.2 \\
\hline 27 & 2 & 3 & 2 & 1 & 3 & 2 & 1 & 2 & 1 & 3 & 1 & 3 & 2 & 63.0 \\
\hline$K_{1}$ & 489.3 & 536.6 & 700.0 & 667.9 & 583.8 & 695.2 & 671.1 & 725.0 & 447.3 & 695.0 & 649.2 & 671.5 & 631.5 & \\
\hline$K_{2}$ & 775.5 & 687.2 & 643.7 & 645.3 & 638.3 & 668.2 & 632.8 & 626.0 & 661.0 & 651.1 & 652.3 & 697.8 & 605.1 & \\
\hline$K_{3}$ & & 724.8 & 604.9 & 635.4 & 726.5 & 585.2 & 644.7 & 597.6 & 840.3 & 602.5 & 647.1 & 579.3 & 712.0 & \\
\hline$k_{1}$ & 54.4 & 59.6 & 77.8 & 74.2 & 64.9 & 77.2 & 74.6 & 80.6 & 49.7 & 77.2 & 72.1 & 74.6 & 70.2 & \\
\hline$k_{2}$ & 86.2 & 76.4 & 71.5 & 71.7 & 70.9 & 74.2 & 70.3 & 69.6 & 73.4 & 72.3 & 72.5 & 77.5 & 67.2 & \\
\hline$k_{3}$ & & 80.5 & 67.2 & 70.6 & 80.7 & 65.0 & 71.6 & 66.4 & 93.4 & 66.9 & 71.9 & 64.4 & 79.1 & \\
\hline$R$ & 31.8 & 20.9 & 4.3 & 2.5 & 6.1 & 3.0 & 4.3 & 14.2 & 43.7 & 10.3 & -0.2 & 2.9 & 2.9 & \\
\hline
\end{tabular}

Note: Duct material (A), relative humidity (B), temperature (C) and growth time (D);

$K_{i}$ : the sum of corresponding colony count when the level on any column is $i$;

$k_{i}: k_{i}=K_{i} / s, s$ is the number of times for each level on any column;

$R$ : range, $R=\operatorname{Max}\left\{k_{i}\right\}-\operatorname{Min}\left\{k_{i}\right\}$ on any column.

differences to fungal growth. However, other interactions of factors made no significant difference to fungal growth. In conclusion, the impact of temperature, relative humidity, duct material and time were interdependent, where the impact of temperature, relative humidity and duct material varied with time.
In addition to the time factor, the optimal condition for DAF growth and reproduction was $\mathrm{A}_{2} \mathrm{~B}_{3} \mathrm{C}_{3}$ : the galvanized iron sheet at $32 \pm 1{ }^{\circ} \mathrm{C}$ and $75 \%-85 \% \mathrm{RH}$. The condition of $\mathrm{A}_{1} \mathrm{~B}_{1} \mathrm{C}_{1}$ (antibacterial composite, $22 \pm 1{ }^{\circ} \mathrm{C}$ and $45 \%-55 \%$ $\mathrm{RH})$ had the strongest inhibitory impact on DAF growth and reproduction. 
Table 9 Orthogonal experiment variance analysis

\begin{tabular}{lccccc}
\hline \multicolumn{1}{c}{ Source of variance } & Sum of squares of deviations & Degree of freedom $(\mathrm{df})$ & Mean square & $F$ & Sig. $(P)$ \\
\hline Model & $161187.758^{\mathrm{a}}$ & 22 & 7326.716 & 205.711 & 0.000 \\
Duct material A & 4279.120 & 1 & 4279.120 & 120.144 & $1.099 \times 10^{-4 * *}$ \\
Relative humidity B & 1482.587 & 2 & 741.294 & 20.813 & $0.004^{* *}$ \\
Temperature C & 796.566 & 2 & 398.283 & 11.183 & $0.014^{*}$ \\
Time D & 5647.803 & 2 & 2823.901 & 79.286 & $1.634 \times 10^{-4 * *}$ \\
Temperature C $\times$ time D & 1383.434 & 2 & 691.717 & 19.421 & $0.004^{* *}$ \\
Relative humidity B $\times$ time D & 798.135 & 4 & 199.534 & 5.602 & $0.043^{*}$ \\
Duct material A $\times$ time D & 1159.115 & 4 & 289.779 & 8.136 & $0.020^{*}$ \\
Duct material A $\times$ temperature C & 85.387 & 2 & 42.694 & 1.199 & 0.376 \\
Duct material A $\times$ relative humidity B & 61.667 & 2 & 30.834 & 0.866 & 0.476 \\
Error & 178.082 & 5 & 35.616 & & \\
Total & 161365.840 & 27 & &
\end{tabular}

Note: ${ }^{a} R^{2}=0.998$ (adjusted $R^{2}=0.992$ );

* represents significant difference;

** represents extremely significant difference.

\subsection{Prediction models for fungal growth}

\subsubsection{One-level model: Logistic model and the Gompertz model}

Figure 10 and Figure 11 present the Logistic models of DAF growth on antibacterial composite and the galvanized iron sheet, respectively. The growth curves presented were built upon the integration of temperature ranges of $22 \pm 1^{\circ} \mathrm{C}, 27 \pm$ $1{ }^{\circ} \mathrm{C}, 32 \pm 1{ }^{\circ} \mathrm{C}$ and relative humidity ranges of $45 \%-55 \%$, $60 \%-70 \%, 75 \%-85 \%$.

Table 10 presents the adjusted $R^{2}$ value, the bias factor $B_{\mathrm{f}}$ and accuracy factor $A_{\mathrm{f}}$ to assess the feasibility and accuracy of the Logistic model in predicting fungal growth. Overall,
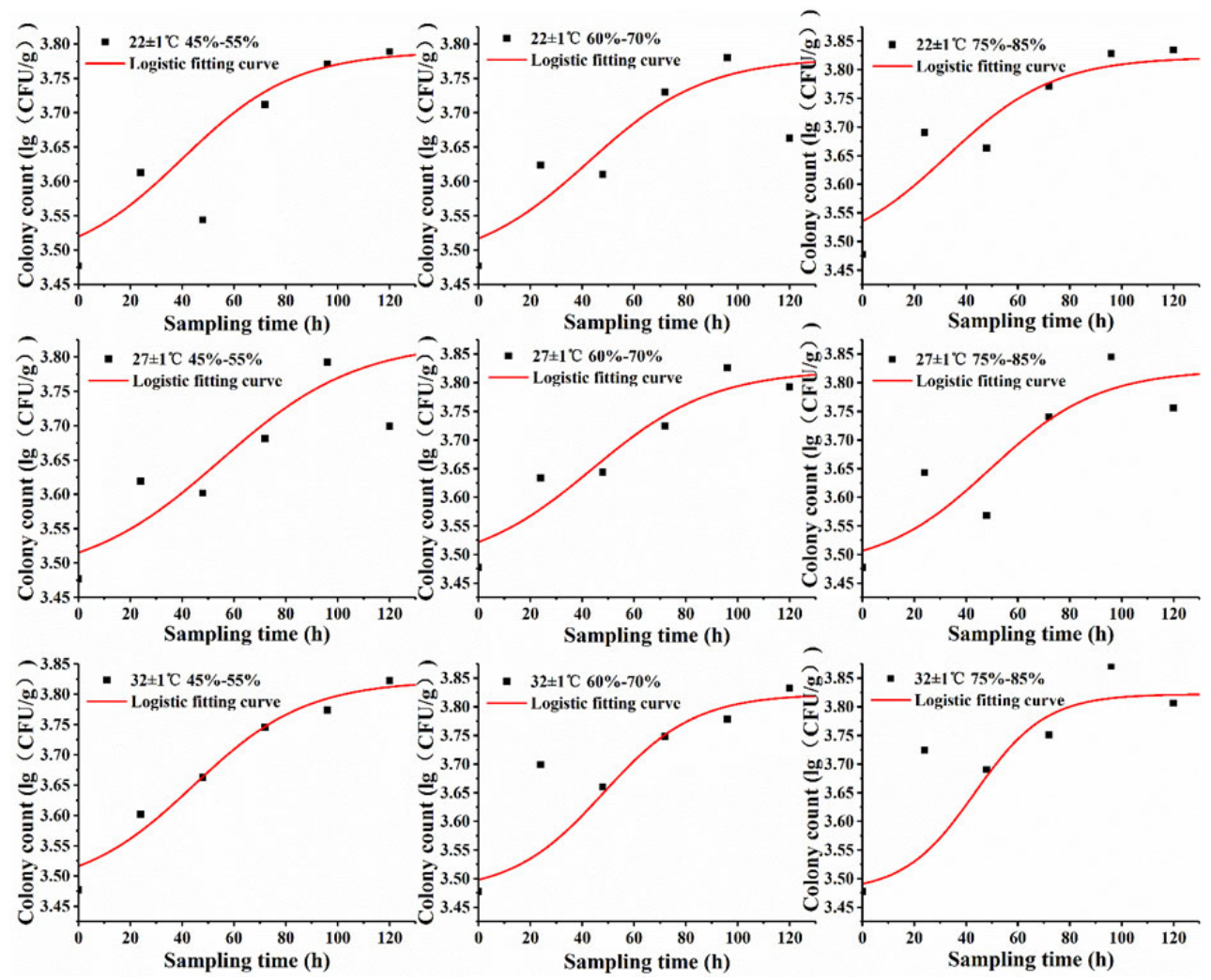

Fig. 10 DAF growth curves on antibacterial composite by the Logistic model 

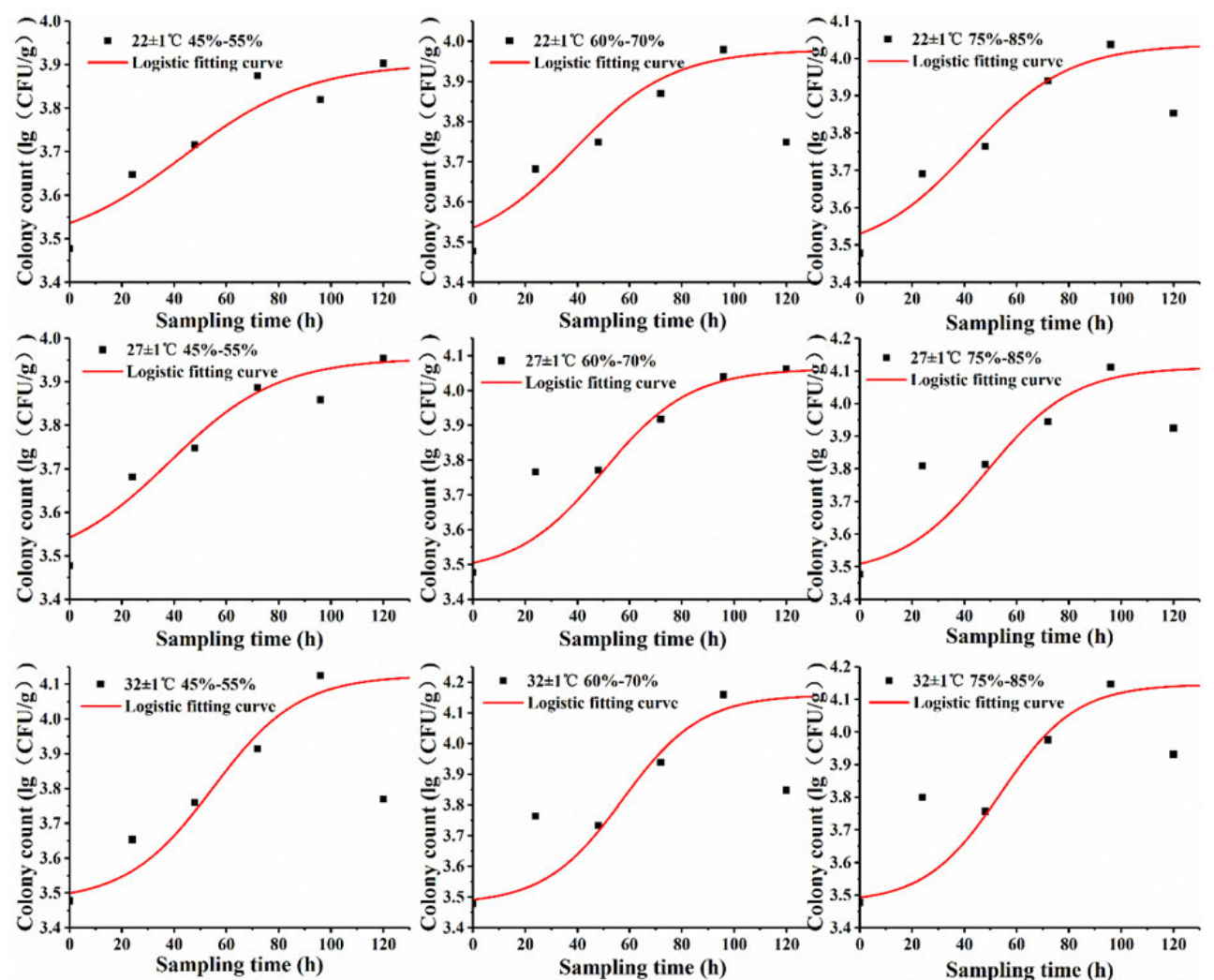

Fig. 11 DAF growth curves on the galvanized iron sheet by the Logistic model

Table 10 Assessment of the accuracy of the Logistic model in predicting fungal growth

\begin{tabular}{|c|c|c|c|c|c|c|c|c|c|}
\hline Duct material & Temperature & Relative humidity (\%) & A & B & $\mathrm{C}$ & M & Adjusted $R^{2}$ & $B_{\mathrm{f}}$ & $A_{\mathrm{f}}$ \\
\hline \multirow{9}{*}{$\begin{array}{l}\text { Antibacterial } \\
\text { composite }\end{array}$} & \multirow{3}{*}{$22 \pm 1^{\circ} \mathrm{C}$} & $45-55$ & 3.4771 & 0.0467 & 0.3118 & 39.7679 & 0.9307 & 1.0082 & 1.0507 \\
\hline & & $60-70$ & 3.4771 & 0.0479 & 0.3153 & 40.4546 & 0.8386 & 0.9985 & 1.0809 \\
\hline & & $75-85$ & 3.4771 & 0.0446 & 0.3575 & 34.3200 & 0.8123 & 1.0042 & 1.0896 \\
\hline & \multirow{3}{*}{$27 \pm 1^{\circ} \mathrm{C}$} & $45-55$ & 3.4771 & 0.0414 & 0.3153 & 49.0116 & 0.8037 & 0.9957 & 1.0905 \\
\hline & & $60-70$ & 3.4771 & 0.0438 & 0.3490 & 44.3486 & 0.8596 & 0.9999 & 1.0841 \\
\hline & & $75-85$ & 3.4771 & 0.0441 & 0.3680 & 51.9553 & 0.7118 & 0.9857 & 1.1234 \\
\hline & \multirow{3}{*}{$32 \pm 1^{\circ} \mathrm{C}$} & $45-55$ & 3.4771 & 0.0505 & 0.3451 & 45.3964 & 0.9582 & 1.0051 & 1.0421 \\
\hline & & $60-70$ & 3.4771 & 0.0523 & 0.3554 & 49.6979 & 0.9742 & 1.0130 & 1.0337 \\
\hline & & $75-85$ & 3.4771 & 0.0562 & 0.3938 & 49.1226 & 0.9455 & 1.0096 & 1.0922 \\
\hline \multirow{9}{*}{$\begin{array}{c}\text { Galvanized iron } \\
\text { sheet }\end{array}$} & \multirow{3}{*}{$22 \pm 1^{\circ} \mathrm{C}$} & $45-55$ & 3.4771 & 0.0420 & 0.4260 & 43.6501 & 0.9128 & 1.0171 & 1.0778 \\
\hline & & $60-70$ & 3.4771 & 0.0528 & 0.5015 & 38.3126 & 0.9261 & 1.0163 & 1.0974 \\
\hline & & $75-85$ & 3.4771 & 0.0533 & 0.5603 & 42.3881 & 0.9401 & 0.9999 & 1.0870 \\
\hline & \multirow{3}{*}{$27 \pm 1^{\circ} \mathrm{C}$} & $45-55$ & 3.4771 & 0.0483 & 0.4771 & 38.1680 & 0.9013 & 1.0328 & 1.0948 \\
\hline & & $60-70$ & 3.4771 & 0.0601 & 0.5855 & 49.9067 & 0.9852 & 1.0125 & 1.0470 \\
\hline & & $75-85$ & 3.4771 & 0.0603 & 0.6341 & 48.7087 & 0.9681 & 1.0079 & 1.0801 \\
\hline & \multirow{3}{*}{$32 \pm 1^{\circ} \mathrm{C}$} & $45-55$ & 3.4771 & 0.0608 & 0.6478 & 54.7566 & 0.9645 & 0.9961 & 1.0825 \\
\hline & & $60-70$ & 3.4771 & 0.0669 & 0.6812 & 57.3261 & 0.9766 & 0.9904 & 1.0677 \\
\hline & & $75-85$ & 3.4771 & 0.0695 & 0.6690 & 53.8418 & 0.9877 & 0.9962 & 1.0494 \\
\hline
\end{tabular}

the adjusted $R^{2}$ was higher than 0.90 except for some special working conditions, indicating Logistic models developed were acceptable to predict fungal growth. Moreover, the capability of the Logistic model to predict fungal growth on the galvanized iron sheet was better than that on antibacterial composite. On the galvanized iron sheet, Logistic model 
had the best predicting capability under high temperature $\left(32 \pm 1{ }^{\circ} \mathrm{C}\right)$, followed by medium temperature $\left(27 \pm 1^{\circ} \mathrm{C}\right)$, and the worst fitting effect under low temperature $\left(22 \pm 1^{\circ} \mathrm{C}\right)$. However, on antibacterial composite, the predicting capability varied with temperature: high temperature $\left(32 \pm 1{ }^{\circ} \mathrm{C}\right)>$ low temperature $\left(22 \pm 1{ }^{\circ} \mathrm{C}\right)>$ medium temperature $(27 \pm$ $1{ }^{\circ} \mathrm{C}$ ). In addition to individual working conditions, for the fungal growth on a galvanized iron sheet, an increase in relative humidity corresponded to the enhanced predicting capability.

The $B_{\mathrm{f}}$ and $A_{\mathrm{f}}$ values of models were also presented in Table 10. The values of $B_{\mathrm{f}}$ were consistently in the range of 0.90-1.05 despite slight fluctuations, indicating that the Logistic model was applicable. The values of $A_{\mathrm{f}}$ were basically in the range of 1.0-1.12 with slight fluctuations, indicating that the accuracy of the Logistic model was acceptable. Therefore, it was feasible and accurate to apply the Logistic model to predict the growth of dust accumulated fungi under the conditions presented in this study.

Figure 12 and Figure 13 present the Gompertz models of DAF growth on antibacterial composite and the galvanized iron sheet, respectively. The growth curves presented were built upon the integration of temperature ranges of $22 \pm 1{ }^{\circ} \mathrm{C}$, $27 \pm 1{ }^{\circ} \mathrm{C}, 32 \pm 1{ }^{\circ} \mathrm{C}$ and relative humidity ranges of $45 \%-55 \%$, $60 \%-70 \%, 75 \%-85 \%$.

Table 11 presents the adjusted $R^{2}$, the bias factor $B_{\mathrm{f}}$ and accuracy factor $A_{\mathrm{f}}$ to assess the feasibility and accuracy of the Gompertz model in predicting fungal growth. According to adjusted $R^{2}$ value, the predicting capability of Gompertz model was acceptable and the predicting capability of fungal growth on the galvanized iron sheet was better than that on antibacterial composite. The predicting capability of the Gompertz model was the strongest at high temperature $\left(32 \pm 1{ }^{\circ} \mathrm{C}\right)$, followed by medium temperature $\left(27 \pm 1^{\circ} \mathrm{C}\right)$ and weakest at low temperature $\left(22 \pm 1^{\circ} \mathrm{C}\right)$. For antibacterial composite, the predicting effect of Gompertz model got better with the decrease in relative humidity.

The $B_{\mathrm{f}}$ and $A_{\mathrm{f}}$ of the Gompertz models were given in Table 11. The $B_{\mathrm{f}}$ ranged between 0.90 and 1.05 with slight fluctuations, indicating that the Gompertz models had good applicability. The $A_{\mathrm{f}}$ was in the range of $1.0-1.16$, while the fluctuations were larger than that of the Logistic model, indicating that the accuracy of the Gompertz model was lower than that of the Logistic model.

Overall, the Gompertz model could be used to predict ADF growth under the experimental conditions considered in this study, but its accuracy was lower than that of the Logistic model.

\subsubsection{Two-level model: Square-root model}

Based on the prediction results of the one-level model, the obtained mean fungal growth rate and corresponding
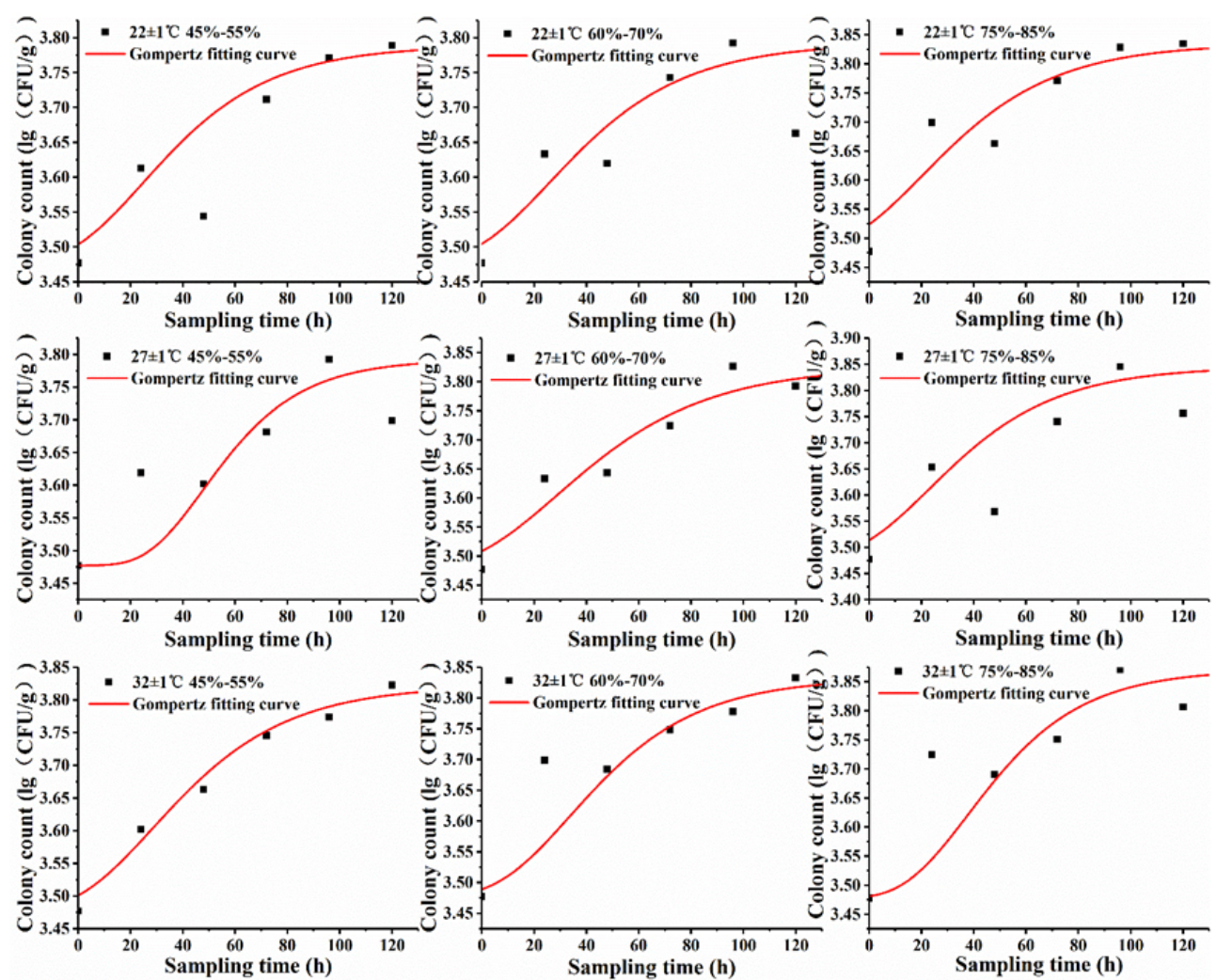

Fig. 12 ADF growth curves on antibacterial composite by the Gompertz model 

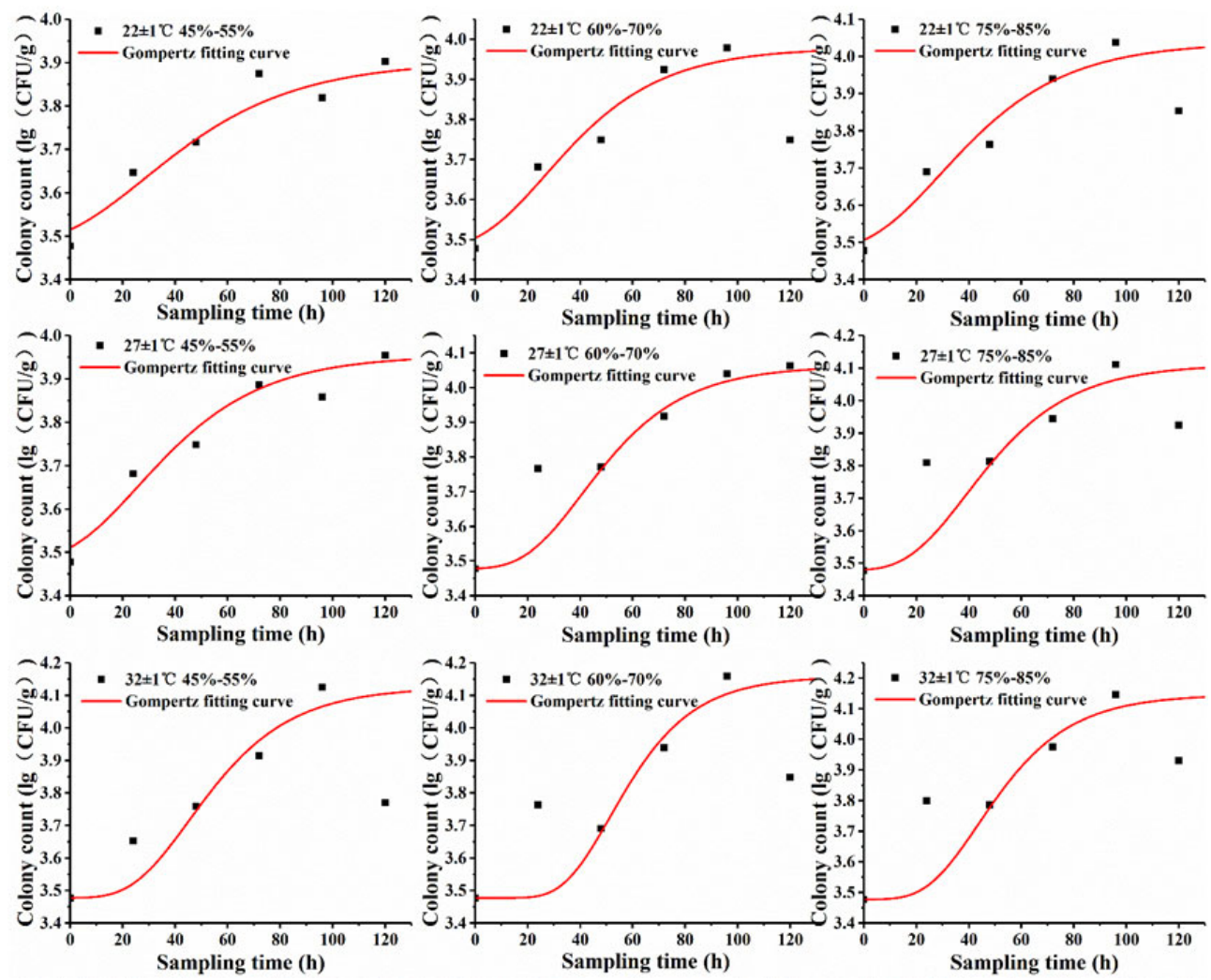

Fig. 13 ADF growth curves on the galvanized iron sheet by the Gompertz model

Table 11 Accuracy of the Gompertz models in predicting ADF growth

\begin{tabular}{|c|c|c|c|c|c|c|c|c|c|}
\hline Duct material & Temperature & Relative humidity (\%) & $A$ & $B$ & C & $M$ & Adjusted $R^{2}$ & $B_{\mathrm{f}}$ & $A_{\mathrm{f}}$ \\
\hline \multirow{9}{*}{$\begin{array}{c}\text { Antibacterial } \\
\text { composite }\end{array}$} & \multirow{3}{*}{$22 \pm 1^{\circ} \mathrm{C}$} & $45-55$ & 3.4771 & 0.0363 & 0.3118 & 24.7549 & 0.9584 & 1.0065 & 1.0427 \\
\hline & & $60-70$ & 3.4771 & 0.0343 & 0.3153 & 26.0672 & 0.8471 & 0.9981 & 1.0800 \\
\hline & & $75-85$ & 3.4771 & 0.0347 & 0.3575 & 20.4790 & 0.8388 & 1.0034 & 1.0869 \\
\hline & \multirow{3}{*}{$27 \pm 1^{\circ} \mathrm{C}$} & $45-55$ & 3.4771 & 0.0471 & 0.3153 & 47.7933 & 0.9536 & 0.9920 & 1.0373 \\
\hline & & $60-70$ & 3.4771 & 0.0311 & 0.3490 & 28.8724 & 0.8698 & 0.9991 & 1.0835 \\
\hline & & $75-85$ & 3.4771 & 0.0361 & 0.3680 & 23.142 & 0.8862 & 1.0124 & 1.0874 \\
\hline & \multirow{3}{*}{$32 \pm 1^{\circ} \mathrm{C}$} & $45-55$ & 3.4771 & 0.0370 & 0.3451 & 27.7826 & 0.9775 & 1.0056 & 1.0372 \\
\hline & & $60-70$ & 3.4771 & 0.0362 & 0.3554 & 33.6629 & 0.9842 & 1.0048 & 1.0296 \\
\hline & & $75-85$ & 3.4771 & 0.0406 & 0.3938 & 37.9218 & 0.9547 & 0.9947 & 1.0486 \\
\hline \multirow{9}{*}{$\begin{array}{c}\text { Galvanized iron } \\
\text { sheet }\end{array}$} & \multirow{3}{*}{$22 \pm 1^{\circ} \mathrm{C}$} & $45-55$ & 3.4771 & 0.0310 & 0.4260 & 28.5887 & 0.9448 & 1.0091 & 1.0658 \\
\hline & & $60-70$ & 3.4771 & 0.0375 & 0.5015 & 27.4034 & 0.9277 & 0.9975 & 1.0937 \\
\hline & & $75-85$ & 3.4771 & 0.0372 & 0.5603 & 29.1670 & 0.9442 & 0.9942 & 1.0866 \\
\hline & \multirow{3}{*}{$27 \pm 1^{\circ} \mathrm{C}$} & $45-55$ & 3.4771 & 0.0369 & 0.4771 & 24.3315 & 0.9388 & 1.0241 & 1.0746 \\
\hline & & $60-70$ & 3.4771 & 0.0460 & 0.5855 & 40.624 & 0.9930 & 1.0114 & 1.1663 \\
\hline & & $75-85$ & 3.4771 & 0.0448 & 0.6341 & 38.9544 & 0.9739 & 0.9899 & 1.0577 \\
\hline & \multirow{3}{*}{$32 \pm 1^{\circ} \mathrm{C}$} & $45-55$ & 3.4771 & 0.0462 & 0.6478 & 45.3298 & 0.9599 & 0.9852 & 1.0722 \\
\hline & & $60-70$ & 3.4771 & 0.0561 & 0.6812 & 51.4914 & 0.9757 & 0.9830 & 1.0594 \\
\hline & & $75-85$ & 3.4771 & 0.0397 & 0.7372 & 45.2861 & 0.9929 & 0.9960 & 1.0332 \\
\hline
\end{tabular}

temperature and relative humidity gradient values were substituted into the two-level model of SRM (Eq. (4)) for predicting ADF growth. Since the Logistic model had higher accuracy, the predicted results obtained by Logistic model were selected for subsequent SRM analysis.

The SRM was initially developed with the only temperature 
consideration (Eq. (4)) for predicting ADF growth on both antibacterial composite and galvanized iron sheet. However, the results indicate that fungal growth on antibacterial composite could not be modeled due to their susceptibility to environmental change. As such, this subsection mainly presents the modified SRM (Eq. (5)) with the consideration of relative humidity $(45 \%-55 \%, 60 \%-70 \%, 75 \%-85 \%)$ and temperature $\left(22 \pm 1{ }^{\circ} \mathrm{C}, 27 \pm 1{ }^{\circ} \mathrm{C}, 32 \pm 1{ }^{\circ} \mathrm{C}\right)$ for predicting the fungal growth on the galvanized iron sheet. The square root predictive values of fungal growth rate obtained by the Logistic model and SRM on the galvanized iron sheet are shown in Table 12 and Table 13, respectively. The actual growth rate and SRM predicted growth rate of fungi on the galvanized iron sheet is presented in Figure 14.

Table 12 Square root predictive values of the ADF growth rate by Logistic model

\begin{tabular}{cccc}
\hline Temperature & $45 \%-55 \%$ & $60 \%-70 \%$ & $75 \%-85 \%$ \\
\hline $22 \pm 1^{\circ} \mathrm{C}$ & 0.20492 & 0.22985 & 0.23080 \\
$27 \pm 1^{\circ} \mathrm{C}$ & 0.21980 & 0.24505 & 0.24556 \\
$32 \pm 1^{\circ} \mathrm{C}$ & 0.246560 & 0.25867 & 0.26359 \\
\hline
\end{tabular}

Table 13 Square root predictive values of growth rate of dust accumulated fungi by SRM

\begin{tabular}{cccc}
\hline Temperature & $45 \%-55 \%$ & $60 \%-70 \%$ & $75 \%-85 \%$ \\
\hline $22 \pm 1{ }^{\circ} \mathrm{C}$ & 0.21059 & 0.22106 & 0.23154 \\
$27 \pm 1^{\circ} \mathrm{C}$ & 0.22741 & 0.23873 & 0.25004 \\
$32 \pm 1^{\circ} \mathrm{C}$ & 0.24307 & 0.25517 & 0.26727 \\
\hline
\end{tabular}

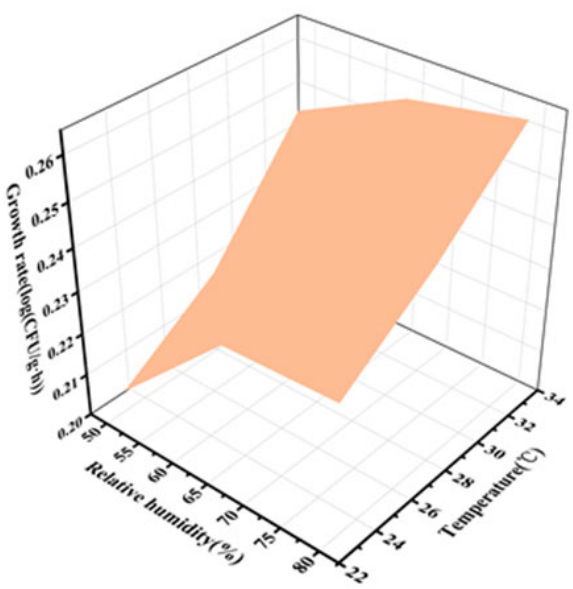

(a)
Table 14 presents the adjusted $R^{2}$, the bias factor $B_{\mathrm{f}}$ and accuracy factor $A_{\mathrm{f}}$ to assess the feasibility and accuracy of revised SRM in predicting fungal growth under the combined effect of temperature and relative humidity. According to Table 14, the adjusted $R^{2}$ of SRM was 0.87 , indicating the predicting effect was acceptable. Under the coupled effect of temperature and relative humidity, the $B_{\mathrm{f}}$ ranged between 0.90 and 1.05 , indicating that the model was suitable for fungal growth prediction under the experimental conditions presented in this study. The $A_{\mathrm{f}}$ was 1.0114 , very close to 1 , indicating that the model had high accuracy.

\section{Conclusions}

This paper presents an in-depth understanding of ADF growth and reproduction in ACV ducts through a holistic set of methods from sequencing, experiment to modeling. Through the analysis, several main conclusions can be drawn.

(1) Except for the filter screen segment in AHU-A, the dust volume in the segments of both AHU-A and B met hygienic specifications of public buildings. The total fungi number in all segments could also meet standard requirements. However, the residual dust volume and fungi in air supply duct and surface cooler segments failed to meet ACV cleansing specification, indicating the cleansing effect was not good.

(2) The dominant genera in each segment were Alternaria (GL1), Alternaria (SF1), Mortierella (SF2), Verticillium (HR1), Nothophoma (GL2), Verticillium (SF3) and

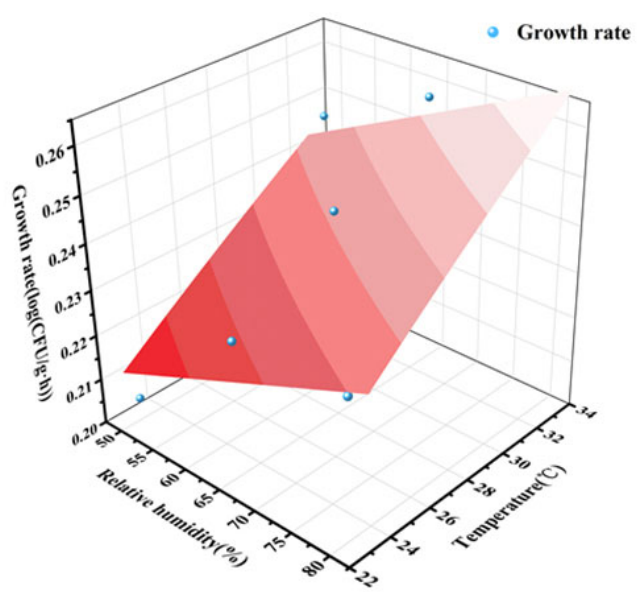

(b)

Fig. 14 Fungal growth rate on the galvanized iron sheet (a) actual fungal growth rate and (b) SRM predicted fungal growth rate

Table 14 Accuracy of SRM in predicting fungal growth

\begin{tabular}{cccccccc}
\hline$b_{2}$ & $T_{\min }$ & $\mathrm{RH}_{\min }$ & $R^{2}$ & Adjusted $R^{2}$ & Times & $B_{\mathrm{f}}$ & $A_{\mathrm{f}}$ \\
\hline $1.2737 \times 10^{-4}$ & -251.416 & -7.08855 & 0.90518 & 0.87357 & 9 & 0.99998 & 1.01140 \\
\hline
\end{tabular}


Aspergillus (HR2) with contents of $17.6 \%, 11.03 \%, 14.79 \%$, $18.72 \%, 15.33 \%, 11.46 \%$ and $20.01 \%$, respectively. The fungi community distribution in HR2 and GL2 were similar, and that in SF1 and SF2 were also similar. The Alternaria_betae-kenyensis, Cladosporium_delicatulum, Aspergillus_sydowii and Verticillium_dahliae were four dominant species in all segments.

(3) The galvanized iron sheet was more suitable for fungal growth and reproduction than antibacterial composite. On both materials, fungal colonies increased with time, peaking at 4 days or 5 days. The increase in relative humidity and temperature were both conducive to fungal growth and reproduction. Fungal growth generally followed the patterns of high humidity $(75 \%-85 \%)>$ medium humidity $(60 \%-70 \%)>$ low humidity $(45 \%-$ $55 \%)$ and high temperature $\left(32 \pm 1^{\circ} \mathrm{C}\right)>$ medium temperature $\left(27 \pm 1^{\circ} \mathrm{C}\right)>$ and low humidity $\left(22 \pm 1^{\circ} \mathrm{C}\right)$.

(4) The impact of duct material (A), relative humidity (B), temperature (C), growth time (D) on fungal growth followed an order of $\mathrm{A}>\mathrm{D}>\mathrm{B}>\mathrm{C}$. $\mathrm{A}, \mathrm{D}, \mathrm{B}$ and the interaction of temperature and time $(\mathrm{C} \times \mathrm{D})$ made extremely significant differences to fungal growth, while $\mathrm{C}, \mathrm{A} \times \mathrm{D}$ and $\mathrm{B} \times \mathrm{D}$ made significant differences. The condition of $\mathrm{A}_{1} \mathrm{~B}_{1} \mathrm{C}_{1}$ (antibacterial composite, $22 \pm 1{ }^{\circ} \mathrm{C}$, $45 \%-55 \% \mathrm{RH})$ had the strongest inhibitory effect on ADF growth.

(5) The capability of one-level model (Logistic model, Gompertz model) in predicting fungal growth on the galvanized iron sheet was better than that on antibacterial composite. The Logistic model exhibited high feasibility and accuracy, according to $B_{\mathrm{f}}(0.90-1.05)$ and $A_{\mathrm{f}}(1.0-1.12)$ values. Gompertz model was also feasible and accurate, while its prediction accuracy was lower than Logistic model, according to $B_{\mathrm{f}}(0.90-1.05)$ and $A_{\mathrm{f}}(1.0-1.16)$ values. Two-level model (SRM) analysis indicated that SRM was feasible and the model accuracy was high, according to $B_{\mathrm{f}}(0.90-1.05)$ and $A_{\mathrm{f}}(1.0114)$ values.

Overall, this paper presents a comprehensive analysis of ADF growth and reproduction. First, this study is of significance to understand the pollution degree of ACV ducts and ADF community composition, structure and diversity. Second, this study is important to understand the impact of duct material, relative humidity, temperature and growth time, which can provide references for inhibiting fungal growth. Third, this study facilitates the understandings of the prediction capability of different models, which can provide references for real-time prediction and timely mitigating fungal contamination in ACV ducts.

Nevertheless, more studies are required to further understand the microbial pollution of ACV systems. Only the ADF growth and reproduction was concerned in this study, while bacteria and virus should be studied in the future. In addition to the associated form of dust accumulation, the study of microbial aerosols in the air and microorganisms in the air-conditioning condensate can be supplemented. This study only discusses the growth of dust accumulated fungi within 5 days. As such a longer period of experiment and multiple high-throughput sequencing may be required to understand the fungal growth and variation of microbial community diversity.

\section{Appendix}

The test facility consists of two parts, including an air duct system and regulatory system (Figure 1). The air duct system is mainly composed of straight ducts, elbow and air valves. The top and side of straight ducts are made of acrylic plates with good transparency, with the cross-section of $0.3 \mathrm{~m} \times$ $0.3 \mathrm{~m}$ and a length of $2 \mathrm{~m}$. The elbow is made of galvanized iron sheet, with an inner radius of $0.2 \mathrm{~m}$ and an outer radius of $0.5 \mathrm{~m}$. The straight duct and the elbow are connected by the flange. The airflow adjusting valves are installed between Elbow 4 and Straight duct 1 (Valve 1) and between Elbow 1 and Straight duct 2 (Value 2). Straight duct 3 is the combined pre-treatment section, including the axial fan, a heating device (electric heating tube), humidification device (mechanical humidifier) and cooling device (surface cooler). Both Straight duct 1 and Straight duct 2 are test sections, equipped with temperature, humidity and supply air velocity sensors. Moreover, the top surface of straight ducts can be unclosed to facilitate sampling from the bottom of air ducts as well as the clean and disinfection of air ducts. Different duct materials can be replaced at the bottom of straight ducts to analyze the impact of duct materials on dust accumulated fungi growth. Through valves 1 and 2, the air volume through straight ducts 1 and 2 can be kept consistent.

The regulatory system consists of an intelligent temperature and humidity controller, two voltage regulators, a mechanical humidifier and a submersible pump. The intelligent temperature and humidity controller are connected with the sensors at one end, and connected with the voltage regulator, humidifier and pump at the other end. The pump relates to the surface cooler. The sensors can real-time detect the temperature and humidity of the airflow in the duct and display them through the controller. It can automatically control the opening and closing of heat source, humidifier and refrigeration device, to control the temperature and humidity in the duct required by the experiment. Two voltage regulators are used to control the input voltage of the fan and heat source respectively, through which the experimental parameters can be changed by changing voltage. The vapor 
supplied by the humidifier is uniformly distributed in the air duct along with the air movement, ensuring the uniformity of humidity in the air duct.

\section{Acknowledgements}

This work was supported by the National Natural Science Foundation of China (No. 51708211, No. 41977368).

\section{References}

Bakó-Biró, Z, Wargocki P, Weschler CJ, Fanger PO (2004). Effects of pollution from personal computers on perceived air quality, SBS symptoms and productivity in offices. Indoor Air, 14: 178-187.

Batterman S, Burge H (1995). HVAC systems as emission sources affecting indoor air quality: A critical review. HVACßR Research, 1: 61-78.

Belanger K, Beckett W, Triche E, Bracken MB, Holford T, et al. (2003). Symptoms of wheeze and persistent cough in the first year of life: Associations with indoor allergens, air contaminants, and maternal history of asthma. American Journal of Epidemiology, 158: 195-202.

Bluyssen PM, Cox C, Seppänen O, de Oliveira Fernandes E, Clausen G, et al. (2003). Why, when and how do HVAC-systems pollute the indoor environment and what to do about it? the European AIRLESS project. Building and Environment, 38: 209-225.

Chang JCS, Foarde KK, VanOsdell DW (1996). Assessment of fungal (Penicillium chrysogenum) growth on three HVAC duct materials. Environment International, 22: 425-431.

Gibson AM, Bratchell N, Roberts TA (1987). The effect of sodium chloride and temperature on the rate and extent of growth of Clostridium botulinum type A in pasteurized pork slurry. Journal of Applied Bacteriology, 62: 479-490.

Gupta S, Khare M, Goyal R (2007). Sick building syndrome-A case study in a multistory centrally air-conditioned building in the Delhi City. Building and Environment, 42: 2797-2809.

Kanaan M, Ghaddar N, Ghali K (2016). Localized air-conditioning with upper-room UVGI to reduce airborne bacteria crossinfection. Building Simulation, 9: 63-74.

Kelley ST, Theisen U, Angenent LT, St Amand A, Pace NR (2004). Molecular analysis of shower curtain biofilm microbes. Applied and Environmental Microbiology, 70: 4187-4192.

Li A, Liu Z, Zhu X, Liu Y, Wang Q (2010). The effect of airconditioning parameters and deposition dust on microbial growth in supply air ducts. Energy and Buildings, 42: 449-454.

Li A, Chen X, Gu C, Gao R, Hu Z (2012a). Prediction of particle deposition in rectangular ventilation ducts. International Journal of Ventilation, 11: 69-78.

Li A, Liu Z, Liu Y, Xu X, Pu Y (2012b). Experimental study on microorganism ecological distribution and contamination mechanism in supply air ducts. Energy and Buildings, 47: 497-505.

Liu Y, Nie Y, Zhang L, Tu F (2005). Impact of cleaning of air conditioning duct systems on indoor inhalable particles and microorganisms. Journal of HV\&AC, 35(2): 77-95. (in Chinese)
Liu Z, Zhu Z, Zhu Y, Xu W, Li H (2015). Investigation of dust loading and culturable microorganisms of HVAC systems in 24 office buildings in Beijing. Energy and Buildings, 103: 166-174.

Liu G, Xiao M, Zhang X, Gal C, Chen X, et al. (2017). A review of air filtration technologies for sustainable and healthy building ventilation. Sustainable Cities and Society, 32: 375-396.

Liu Z, Ma S, Cao G, Meng C, He B (2018). Distribution characteristics, growth, reproduction and transmission modes and control strategies for microbial contamination in HVAC systems: A literature review. Energy and Buildings, 177: 77-95.

Liu Z, Yin H, Ma S, Wei B, Jensen B, Cao G (2019). Effect of environmental parameters on culturability and viability of dust accumulated fungi in different HVAC segments. Sustainable Cities and Society, 48: 101538.

Lu Z, Zhang J, Cao D, Huang X (2007). Testing and analysis for microbes and particles in central air conditioning systems of public buildings. Journal of HVઐAC, 37(1): 103-107. (in Chinese)

Maddalena R, Mendell MJ, Eliseeva K, Chan WR, Sullivan DP, et al. (2015). Effects of ventilation rate per person and per floor area on perceived air quality, sick building syndrome symptoms, and decision-making. Indoor Air, 25: 362-370.

McDonald K, Sun D-W (1999). Predictive food microbiology for the meat industry: a review. International Journal of Food Microbiology, 52: 1-27.

McMeekin TA, Chandler RE, Doe PE, Garland CD, Olley J, et al. (1987). Model for combined effect of temperature and salt concentration/water activity on the growth rate of Staphylococcus xylosus. Journal of Applied Bacteriology, 62: 543-550.

McMeekin TA, Olley J, Ratkowsky DA, Ross T (2002). Predictive microbiology: towards the interface and beyond. International Journal of Food Microbiology, 73: 395-407.

Mendell MJ, Lei-Gomez Q, Mirer A, Seppanen O, Brunner G (2006). Risk Factors in Heating, Ventilating, and Air-Conditioning Systemsfor Occupant Symptoms in US Office Buildings: The EPA BASE Study. Ernest Orlando Lawrence Berkeley NationalLaboratory, Berkeley, CA USA.

Mendell MJ, Mirer AG, Cheung K, Tong M, Douwes J (2011). Respiratory and allergic health effects of dampness, mold, and dampness-related agents: a review of the epidemiologic evidence. Environmental Health Perspectives, 119: 748-756.

Meng C, Wang Q, Song Y, Cao Y, Zhao N, Shi Y (2015). Experimental study on both cleaning effect and motion performance of the duct-cleaning robot. Sustainable Cities and Society, 14: 64-69.

$\mathrm{MOH}$ (2012a). Hygienic specification of central air conditioning ventilation system in public buildings. Ministry of Health of China. (in Chinese)

MOH (2012b). Specification for cleaning and disinfection of central air conditioning ventilation system in public buildings. Ministry of Health of China. (in Chinese)

Noris F, Siegel JA, Kinney KA (2009). Biological and metal contaminants in HVAC filter dust. ASHRAE Transactions, 115(2): 484-491.

Oladokun MO, Ali M, Osman SB, Lin Z (2017). Indoor mould growth prediction using coupled computational fluid dynamics and mould growth model. Building Simulation, 10: 551-562. 
Pakarinen J, Hyvärinen A, Salkinoja-Salonen M, Laitinen S, Nevalainen A, et al. (2008). Predominance of Gram-positive bacteria in house dust in the low-allergy risk Russian Karelia. Environmental Microbiology, 10: 3317-3325.

Pitkäranta M, Meklin T, Hyvärinen A, Paulin L, Auvinen P, et al. (2008). Analysis of fungal flora in indoor dust by ribosomal DNA sequence analysis, quantitative PCR, and culture. Applied and Environmental Microbiology, 74: 233-244.

Price DL, Simmons RB, Ezeonu IM, Crow SA, Ahearn DG (1994). Colonization of fiberglass insulation used in heating, ventilation and air conditioning systems. Journal of Industrial Microbiology, 13: $154-158$.

Qudiesat K, Abu-Elteen K, Elkarmi A, Hamad M, Abussaud M (2009). Assessment of airborne pathogens in healthcare settings. African Journal of Microbiology Research, 3(2): 066-076.

Ratkowsky DA, Olley J, McMeekin TA, Ball A (1982). Relationship between temperature and growth rate of bacterial cultures. Journal of Bacteriology, 149: 1-5.

Rintala H, Pitkäranta M, Toivola M, Paulin L, Nevalainen A (2008). Diversity and seasonal dynamics of bacterial community in indoor environment. BMC Microbiology, 8: 56.

Ross T (1996). Indices for performance evaluation of predictive models in food microbiology. Journal of Applied Bacteriology, 81: 501-508.

Satish U, Mendell MJ, Shekhar K, Hotchi T, Sullivan D, et al. (2012). Is $\mathrm{CO}_{2}$ an indoor pollutant? Direct effects of low-to-moderate $\mathrm{CO}_{2}$ Concentrations on human decision-making performance. Environmental Health Perspectives, 120: 1671-1677.

Seppänen O, Fisk WJ (2002). Association of ventilation system type with SBS symptoms in office workers. Indoor Air, 12: 98-112.
Seppänen O (2008). Ventilation strategies for good indoor air quality and energy efficiency. International Journal of Ventilation, 6: 297-306.

Toivola M, Alm S, Reponen T, Kolari S, Nevalainen A (2002). Personal exposures and microenvironmental concentrations of particles and bioaerosols. Journal of Environmental Monitoring, 4: $166-174$.

Wang C (2016). Study on the microorganism contamination and the effect of hygrothermal response in air handling unit. Master Thesis, Dalian University of Technology, China. (in Chinese)

Whiting RC, Buchanan RL (1993). A classification of models in predictive microbiology-A reply to KR Davey. Food Microbiology, 10: $175-177$.

Wilson SC, Palmatier RN, Andriychuk LA, Martin JM, Jumper CA, et al. (2007). Mold contamination and air handling units. Journal of Occupational and Environmental Hygiene, 4: 483-491.

$\mathrm{Xu} \mathrm{R}$ (2013). Species identification and thermal response analysis of microbial contaminants in accumulated dust in air-conditioned wind systems. Master Thesis, Zhongkai University of Agriculture and Engineering, China. (in Chinese)

Yu XH, Che FX (1998). Modern Air Microbiology and Technology of Sampling, Inspection. Beijing: Military Medical Press. (in Chinese)

Zhou Q, Gao T (2000). Environmental Engineering Microbiology, 2nd end. Beijing: Higher Education Press.

Zhu X (2009). Effect of air conditioning parameters on microbial growth in dust accumulated in supply air duct. Master Thesis, Xi'an University of Architecture and Technology, China. (in Chinese) 